Article

\title{
New Material of Paleocene-Eocene Pellornis (Aves: Gruiformes) Clarifies the Pattern and Timing of the Extant Gruiform Radiation
}

\author{
Grace Musser 1,*(D), Daniel T. Ksepka ${ }^{2}$ and Daniel J. Field ${ }^{3, *(D)}$ \\ 1 Department of Geological Sciences, University of Texas at Austin, Austin, TX 78712, USA \\ 2 Bruce Museum, Greenwich, CT 06830, USA \\ 3 Department of Earth Sciences, University of Cambridge, Cambridge, CB2 3EQ, UK \\ * Correspondence: gmusser@utexas.edu (G.M.); djf70@cam.ac.uk (D.J.F.)
}

Received: 10 May 2019; Accepted: 26 June 2019; Published: 28 June 2019

\begin{abstract}
Pellornis mikkelseni is an early gruiform from the latest Paleocene-earliest Eocene Fur Formation of Denmark. At approximately 54 million years old, it is among the earliest clear records of the Gruiformes. The holotype specimen, and only material thus far recognised, was originally considered to comprise a partial postcranial skeleton. However, additional mechanical preparation of the nodule containing the holotype revealed that the skeleton is nearly complete and includes a well-preserved skull. In addition to extracting new information from the holotype, we identify and describe two additional specimens of P. mikkelseni which reveal further morphological details of the skeleton. Together, these specimens show that P. mikkelseni possessed a schizorhinal skull and shared many features with the well-known Paleogene Messelornithidae ("Messel rails"). To reassess the phylogenetic position of P. mikkelseni, we modified an existing morphological dataset by adding 20 characters, four extant gruiform taxa, six extinct gruiform taxa, and novel scorings based on the holotype and referred specimens. Phylogenetic analyses recover a clade containing P. mikkelseni, Messelornis, Songzia and crown Ralloidea, supporting P. mikkelseni as a crown gruiform. The phylogenetic position of $P$. mikkelseni illustrates that some recent divergence time analyses have underestimated the age of crown Gruiformes. Our results suggest a Paleocene origin for this important clade, bolstering evidence for a rapid early radiation of Neoaves following the end-Cretaceous mass extinction.
\end{abstract}

Keywords: avian phylogeny; Neoaves; Gruiformes; evolution; morphology; divergence time estimation; biogeography; diversification

\section{Introduction}

Extant Gruiformes comprise six family-level clades: finfoots (Heliornithidae), flufftails (Sarothruridae), rails (Rallidae), trumpeters (Psophiidae), the monotypic limpkin (Aramidae), and cranes (Gruidae). Gruiformes is further subdivided into Ralloidea (Heliornithidae, Sarothruridae, Rallidae) and Gruoidea (Psophiidae, Aramidae, Gruidae)—a division uniformly supported across recent phylogenetic studies [1-18]. Given lingering uncertainty regarding neoavian relationships more generally, an improved understanding of the fossil record and phylogenetic history of Gruiformes is critical, with important implications for addressing longstanding questions regarding early neoavian divergence times [1-7] and historical biogeography [5,8-12].

Several morphological and molecular phylogenetic studies have attempted to resolve the higher-level interrelationships of extant Gruiformes [13-17]. Although the phylogenetic interrelationships of taxa within Gruoidea are now largely agreed upon, conflicting relationships within Ralloidea continue to arise from both 
morphological and molecular studies [3,5,12-18]. Specifically, the composition and phylogenetic position of the rail-like Sarothruridae with respect to Heliornithidae and Rallidae remains controversial $[12,17,18]$, with implications for informing macroevolutionary patterns within Ralloidea.

To shed new light on these questions, a reassessment of the gruiform fossil record in the context of contemporary avian systematics is critical. The Paleogene fossil record of Gruiformes is extensive, but the phylogenetic position of even well-known taxa remains uncertain $[19,20]$. Several recent molecular divergence time studies have advocated a relatively recent, late Eocene age for crown Gruiformes $[1,3,5]$. Conflicting with this temporal scenario, however, many Paleogene ralloid-like fossils have been recovered from Europe, suggesting that crown Gruiformes may have diverged earlier in the Cenozoic $[19,20]$ and citations therein. This includes a ralloid-like, fragmentary distal tarsometatarsus from Belgium and a ralloid-like right coracoid from France that date to the Paleocene [21]. Problematically, the precise affinities of many such fossils remain questionable as they are fragmentary and/or poorly preserved [22,23].

The most complete and well-preserved Paleogene ralloid-like fossils belong to Messelornithidae (Messel rails). Messelornithidae are extremely well-represented, with over 500 specimens recovered from various localities [24-26]. Several of these specimens are virtually complete, and some exhibit three-dimensional preservation $[19,20,27]$. At present, Messelornithidae is hypothesized to comprise Messelornis nearctica Hesse, 1992 [24] of the Eocene Green River Formation of North America [20,24,27,28]; Messelornis cristata Hesse, 1988 [25] of the Eocene Messel Formation of Germany; Messelornis russelli Mourer-Chauviré, 1995 [29] of the Paleocene of France; and Itardiornis hessae Mourer-Chauviré, 1995 [29] of the late Eocene to early Oligocene Quercy fissure fillings of France. Messelornithidae was initially hypothesized to represent the sister-taxon of the extant monotypic sunbittern (Eurypyga helias) of the neotropics [14,29-33]. However, more recently Messelornithidae has been considered to represent the sister-taxon of Ralloidea [19,34], or the sister-taxon of Rallidae [35]. Thus, the phylogenetic position of these most abundantly represented Paleogene fossil birds remains uncertain $[19,20]$.

Pellornis mikkelseni Bertelli et al., 2011 [35] and Songzia acutunguis Wang et al., 2012 [36] are two ralloid-like taxa that have been hypothesized to be closely related to the Messelornithidae. However, few fossil specimens of these taxa have been recovered and phylogenetic analyses have yielded partially conflicting results regarding their affinities $[35,36]$. Songzia is known from two species recovered from the Eocene Yangxi Formation of Hubei Province, China [36,37] and a putative specimen from the Paleocene of France [38]. Songzia acutunguis is represented by the best preserved material [36]. Wang et al. [36] assessed the phylogenetic placement of S. acutunguis and recovered it either in a polytomy with other Gruiformes and outgroup taxa or within a clade including all Rallidae with the exception of Himantornis when exploring alternative matrices.

The holotype specimen of P. mikkelseni (MGUH 29278) was collected from the latest Paleocene-earliest Eocene Fur Formation of Denmark and is approximately 54 million years old [35]. It is well-preserved and comprises a skeleton with contour feathers that have a "furry pelage-like appearance," which partly inspired the genus name Pellornis [35]. Pellornis mikkelseni was initially hypothesized to share close relationships with Galliformes due to the presence of intratendinous ossification in the holotype specimen [39], but was subsequently aligned with Messelornithidae [40]. Bertelli et al. [35] formally described the species. Their implied-weights parsimony analysis of 83 morphological characters placed P. mikkelseni as the sister-taxon of M. cristata with low support (38\% jackknife value and two unambiguous synapomorphies). Messelornithidae (represented by P. mikkelseni+M. cristata) was in turn recovered as the sister-group to Rallidae (represented in that study by Limnocorax flavirostra and Gallinula chloropus).

The phylogenetic placement of P. mikkelseni has particularly important implications for the timing of gruiform diversification, as recent genomic studies have recovered conflicting estimates for divergence times within Gruiformes (summarized in Table 1). Analyses of mitochondrial sequences have typically resulted in relatively old divergence estimates, with crown Gruiformes originating around the K-Pg boundary. In contrast, studies based on nuclear genes and whole genomes have tended to yield 
younger estimates, with crown Gruiformes originating later in the Paleocene or Eocene. Reevaluating internal gruiform calibration points for divergence time analyses is therefore critical, as the phylogenetic placement of Paleogene taxa such as P. mikkelseni remain variable. Clarifying gruiform divergence dates is crucial not only for a better understanding of the evolution of Gruiformes, but also for clarifying the early evolutionary history of Neoaves more generally.

Table 1. Recently published divergence dates for Gruiformes and its major subclades. Mean ages are provided with $95 \%$ highest posterior density intervals in parentheses. Dates are estimated from published figures with the exception of those from Boast et al. [18] and the upper bound of Gruiformes in Claramunt and Cracraft [5]. Prum et al. [3] employed over 390,000 bases of genomic sequence data. Claramunt and Cracraft [5] used first and second codon positions of 1156 clock-like exons from Jarvis [2] (124,196 bases in total). García R et al. [16] used mitochondrial genomes. García R et al. [17] used partial sequences of several mitochondrial genes (cytb, COI, 16S, 2900 base pairs) and fragments from two nuclear genes (FGB-7 and RAG-1, 1900 base pairs). Boast et al. [18] used largely complete mitochondrial genomes.

\begin{tabular}{|c|c|c|c|c|c|}
\hline Taxon & $\begin{array}{l}\text { Prum et al. [3] } \\
\text { (nuclear) }\end{array}$ & $\begin{array}{c}\text { Claramunt and Cracraft } \\
\text { [5] (nuclear) }\end{array}$ & $\begin{array}{l}\text { García R et al. } \\
\text { [16] (mtDNA) }\end{array}$ & $\begin{array}{l}\text { García R et al. } \\
\text { [17] (mtDNA) }\end{array}$ & $\begin{array}{l}\text { Boast et al. [18] } \\
\text { (mtDNA) }\end{array}$ \\
\hline Gruiformes & $\begin{array}{c}\text { mid-Eocene } 39 \\
\text { (29-61) Ma }\end{array}$ & $\begin{array}{c}\text { Paleocene-Eocene } \\
\text { boundary } 57 \text { (62-52.0) Ma }\end{array}$ & $\begin{array}{l}\text { K-Pg boundary } \\
67(75-59) \mathrm{Ma}\end{array}$ & $\begin{array}{l}\text { K-Pg boundary } \\
65 \text { (74-57) Ma }\end{array}$ & $\begin{array}{c}\text { K-Pg boundary } \\
65.4(52.0-80.4) \mathrm{Ma}\end{array}$ \\
\hline Gruoidea & $\begin{array}{l}\text { early Oligocene } \\
32(52-15) \mathrm{Ma}\end{array}$ & mid-Eocene 42 (55-25) Ma & $\begin{array}{l}\text { late Eocene } 35 \\
(52-23) \mathrm{Ma}\end{array}$ & $\begin{array}{l}\text { late Eocene } 35 \\
\text { (46-26) Ma }\end{array}$ & $\begin{array}{c}\text { Paleocene } \\
59.1(43.6-76.9) \mathrm{Ma}\end{array}$ \\
\hline Ralloidea & $\begin{array}{l}\text { mid-Oligocene } \\
29(46-16) \mathrm{Ma}\end{array}$ & mid-Eocene 43 (54-32) Ma & $\begin{array}{l}\text { early Eocene } 52 \\
(60-44) \mathrm{Ma}\end{array}$ & $\begin{array}{l}\text { mid-Paleocene } \\
60(70-52) \mathrm{Ma}\end{array}$ & $\begin{array}{c}\text { early Eocene } 54.7 \\
(41.4-70.0) \mathrm{Ma}\end{array}$ \\
\hline Rallidae & $\begin{array}{l}\text { early Miocene } \\
16(26-4) \mathrm{Ma}\end{array}$ & mid-Eocene 43 (54-32) Ma & $\begin{array}{c}\text { mid-Eocene } 41 \\
(48-33) \mathrm{Ma}\end{array}$ & $\begin{array}{l}\text { late Eocene } 38 \\
(45-32) \mathrm{Ma}\end{array}$ & $\begin{array}{l}\text { late Eocene } 40.5 \\
(28.4-53.9) \mathrm{Ma}\end{array}$ \\
\hline
\end{tabular}

In this study, we describe numerous novel elements from the Pellornis mikkelseni holotype based on additional preparation of the holotype specimen and refer and describe two additional specimens of P. mikkelseni. Together, these three specimens provide substantial new anatomical information on P. mikkelseni and facilitate a nearly complete osteological description. Based on this new information, we reassess the phylogenetic position of P. mikkelseni by expanding character and taxon sampling of a recent phylogenetic matrix and revising previous scorings for P. mikkelseni. We recover P. mikkelseni at the base of Ralloidea in a clade containing Messelornis and Songzia, illustrating that recent divergence time analyses based on nuclear and genomic data have underestimated the age of crown Gruiformes.

\section{Materials and Methods}

\subsection{Material and Geological Setting}

The holotype specimen MGUH 29278 and referred specimen DK664 are held within the Paleontological type collection of the Geologisk Museum at the University of Copenhagen. Referred specimen FUM 1681a is housed in the collections of Museum Salling-Naturhistorie in Nederby, Denmark. All Pellornis specimens were originally encased in calcareous silt-stone concretions from the Fur Formation of Denmark. Two volcanic ash layers within this formation have been assigned ages of 54.5 and 54.0 Ma via 39Ar/40Ar-dating [35,41]. Although it remains unknown whether the horizons from which the fossils were collected are located above, below, or between these dated layers, the provenance of all is known to be close to the 54.0-54.5 Ma interval. FUM 1681a was specifically associated with ash layer +19 of the Silstrup Member by lithological similarity [42] and thus dates to $54.09 \mathrm{Ma}+/-0.14 \mathrm{Ma}$ [41]. Additional information regarding the geological setting of the holotype is detailed in Bertelli et al. [35]. Comparative material used for description and phylogenetic analysis came from the Division of Vertebrate Zoology of the Peabody Museum of Natural History, Yale University (YPM); the National Bird Collection of the National Museum of Natural History (USNM); the Ornithology Collection of the American Museum of Natural History $(\mathrm{AMNH})$; and the Texas Memorial Museum of the University of Texas at Austin (M). Anatomical 
terminology largely follows that of Baumel and Witmer [43]. Measurements are provided in millimeters and are rounded to the nearest $0.1 \mathrm{~mm}$ (Table 2). Specimen numbers for comparative material are provided in Table 3.

\subsection{Character Matrix}

We added 20 characters, four extant gruiform taxa, six extinct gruiform taxa, and novel scorings based on the Pellornis mikkelseni holotype specimen, newly referred specimens of P. mikkelseni, and comparative material to the dataset of Bertelli et al. [35], which includes a subset of 58 morphological characters from the dataset of Mayr and Clarke [44]. Our total dataset consists of 102 characters and 36 taxa (8 extinct, 28 extant). The extant gruiform taxa added to the dataset include four members of Ralloidea: Himantornis haematopus petiti (nkulengu rail), Sarothrura pulchra (white-spotted flufftail), Porphyrio flavirostris (azure gallinule), and Rallus longirostris (mangrove rail). We added the extinct ralloids Messelornis nearctica, Itardiornis hessae, Songzia acutunguis, Australlus gagensis Worthy et al., 2011 [45] and A. disneyi Worthy et al., 2011 [45]. Australlus was added as it has been hypothesized to be messelornithid [19]. We coded one extinct member of Gruoidea, Parvigrus pohli Mayr, 2005 [46], based on the descriptions of Mayr [46,47] (which include provisionally referred Belgian material [47]). Himantornis was included because this taxon has at times been hypothesized to represent the sister taxon of all other extant rails [14,48]; but see [18]. S. pulcra was included to represent Sarothruridae, a ralloid group hypothesized to represent the sister-group of Heliornithidae $[3,17,49]$. Tinamus solitarius (solitary tinamou), representing Palaeognathae, was designated as the outgroup as in Bertelli et al. [35]. Character descriptions are provided in the Appendix A and the data matrix has been made publicly available on Morphobank [50] under Project 3456 (http://morphobank.org/permalink/?P3456) in the Supplementary Materials.

Table 2. Selected measurements (right/left, in mm) of the holotype specimen, MGUH 29278, and two referred specimens (DK664 and FUM 1681a) of Pellornis mikkelseni.

\begin{tabular}{|c|c|c|c|}
\hline Element & MGUH 29278 & DK664 & FUM 1681a \\
\hline Skull (total length) & 50.3 & 48.5 & \\
\hline Synsacrum (total length) & 45.7 & & \\
\hline \multicolumn{4}{|c|}{ Cranial margin of synsacrum to caudal margin of pubis } \\
\hline Femur (total length) & 41.1 & & 39.1 \\
\hline Femur (midshaft width) & & & 3.0 \\
\hline Tibiotarsus (total length) & & & 69.1 \\
\hline
\end{tabular}

Table 3. Specimen numbers of newly added taxa and skeletal specimens used for comparison during fossil description. The institutional abbreviation key is provided in Materials and Methods.

\begin{tabular}{cc}
\hline Group Name & Species Sampled and Specimen Numbers \\
\hline Charadriiformes & Larus smithsonianus (YPM 102675) \\
Gruoidea & $\begin{array}{c}\text { Psophia crepitans (AMNH 29322, YPM 102505, USNM 320971, USNM 429974), Aramus guarauna } \\
\text { (AMNH 24194, YPM 102505, USNM 612025, USNM 226809), Balearica regulorum (YPM 105863, } \\
\text { AMNH 10699) }\end{array}$ \\
Heliornis fulica (USNM 345807, USNM 623068, USNM 19159, USNM 321493, YPM 109145), \\
Ralloidea & USNM 501940, USNM 525876), Himantornis haematopus (AMNH 4183, USNM 318581), Gallinula \\
& chloropus (AMNH 28451, YPM 103042, USNM 499259), Fulica cornuta (AMNH 10207, M-11460), \\
Eurypygidae & Porphyrio flavirostris (YPM 109144), Amaurornis flavirostra (YPM 103778), Aramides ypecaha (YPM 101029, \\
Rhynochetidae & USNM 614591, USNM 635722, USNM 614593) \\
Extinct Taxa & Eurypyga helias (AMNH 3750, AMNH 4293, USNM 623251) \\
Rhynochetos jubatus (AMNH 1326, AMNH 554, USNM 612087)
\end{tabular}




\subsection{Body Size Estimation}

Midshaft femur diameter provides an especially precise correlate of body mass in extant volant birds $\left(R^{2}=0.932\right)$ [51]. Thus, we estimated the live body mass of P. mikkelseni (mean body mass estimate with $95 \%$ upper and lower prediction intervals) based on the complete, three-dimensionally preserved femur of FUM 1681a.

\subsection{Phylogenetic Analysis}

We performed unconstrained heuristic parsimony analyses of the dataset in PAUP* [52] (Version 4.0a, build $164(\times 86)$ ) using 10,000 random taxon addition replicates. No character weighting was applied. Bootstrap analyses were performed using 100 bootstrap replicates each with 1000 random taxon addition replicates. Characters 33, 55, 76, 92, and 97 were ordered, following Bertelli et al. [35]. Constrained analyses were also performed using the topology of a recent phylogenomic study [3] as a molecular backbone constraint for all sampled extant taxa, with extinct taxa left unconstrained.

\section{Results}

\subsection{Systematic Paleontology}

Aves Linnaeus, 1758 [53].

Neognathae Pycraft, 1900 [54].

Messelornithidae Hesse, 1988 [25].

Pellornis Bertelli et al., 2011 [35].

\subsubsection{Type Species}

Pellornis mikkelseni Bertelli et al., 2011 [35].

\subsubsection{Emended Differential Diagnosis}

Pellornis mikkelseni differs from other messelornithid species in the following combination of character states: (1) Slit-like caudal margin of the nares (unlike the rounded caudal margins of the nares of Messelornis nearctica and Songzia acutunguis); (2) nares extending caudally beyond the zona flexoria craniofacialis (unlike the more rostrally positioned nares of Messelornis cristata); (3) a larger femur length to carpometacarpus length ratio (197\%) versus that of M. cristata (a range of 155-161\%) [35] and M. nearctica (184\%) [35]; (4) more strongly projected carina of the sternum; (5) deep incisurae mediales of the sternum; and (6) cup-like cotyla scapularis on the coracoid (shallow in Itardiornis hessae [29]).

\subsubsection{Holotype Specimen}

MGUH 29278, a nearly complete articulated skeleton of an adult individual preserved within two slabs (Figures 1 and 2).

Type locality. Collected at the base of a cliff northeast of Sundby, on the island of Mors, northwestern Jutland, Denmark, latest Paleocene-earliest Eocene [35].

Measurements. See Table 2. 


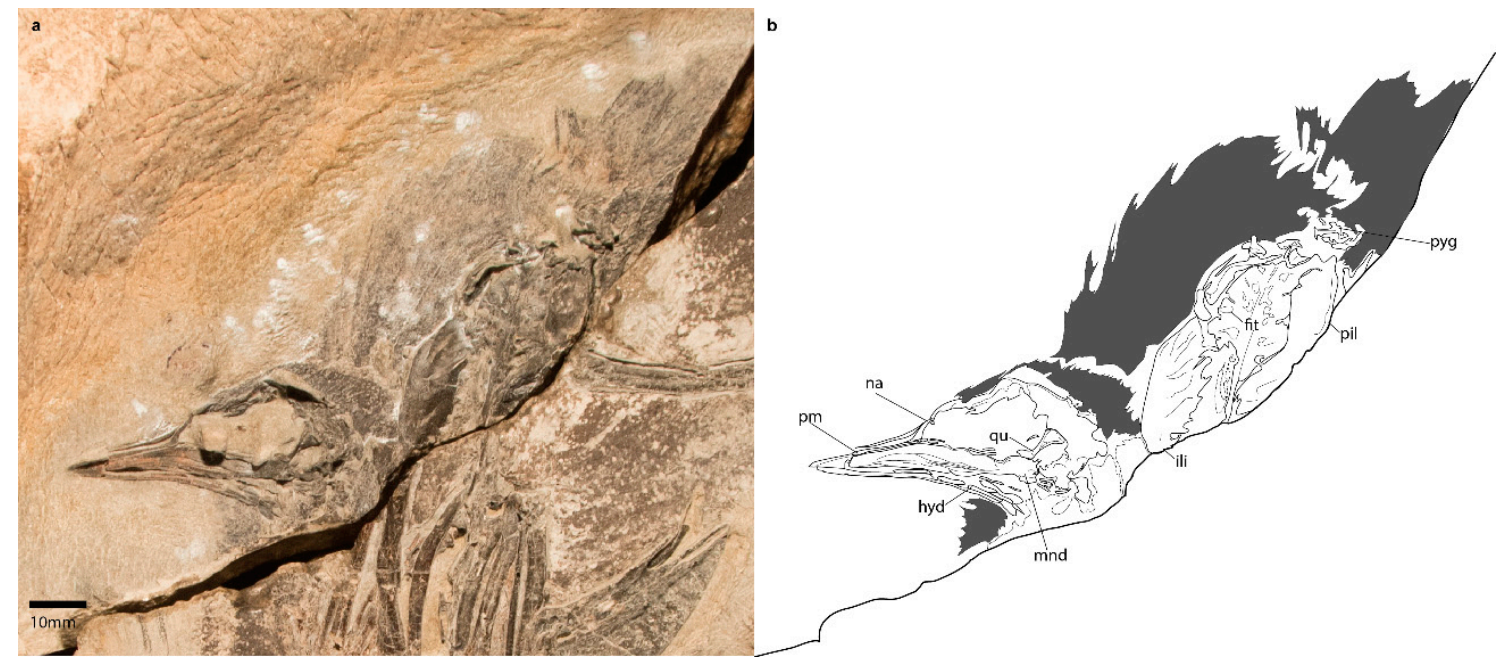

Figure 1. Photograph (a) and line drawing (b) of the holotype specimen of Pellornis mikkelseni, MGUH 29278. Soft tissue and plumage is filled in with gray. Dashed borders indicate bone that is extremely broken. Anatomical abbreviations: pm premaxilla, na narial bar, pal palatines, qu quadrate, mnd mandible, hyd hyoids, ili preacetabular ilium, pil postacetabular ilium, fit foramen intertransversarium, pyg pygostyle.
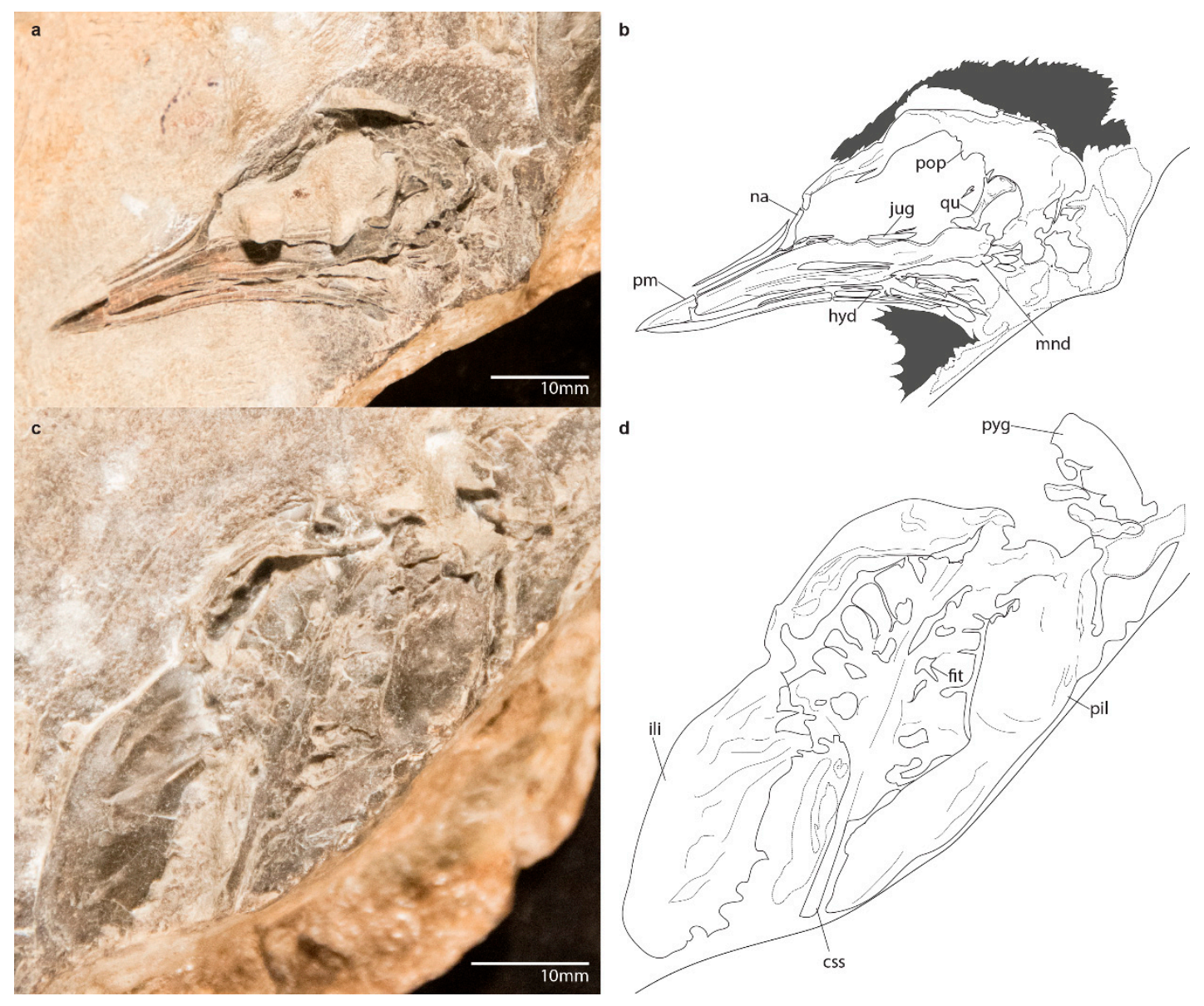

Figure 2. Photographs (a, skull in lateral aspect and c, pelvis in dorsal aspect) and line drawings (b, d) of the holotype specimen of Pellornis mikkelseni, MGUH 29278. Soft tissue and plumage is filled in with gray. Dashed borders indicate bone that is extremely broken. Anatomical abbreviations: pm premaxilla, na narial bar, pop postorbital process, pal palatines, qu quadrate, jug jugal, mnd mandible, hyd hyoids, ili preacetabular ilium, pil postacetabular ilium, fit foramen intertransversarium, pyg pygostyle. 


\subsubsection{Referred Specimen}

DK664, a partial skeleton and skull preserved on one slab (Figures 3 and 4).

Locality. Fur Formation, Mors, northwestern Jutland, Denmark, latest Paleocene-earliest Eocene. Measurements. See Table 2.

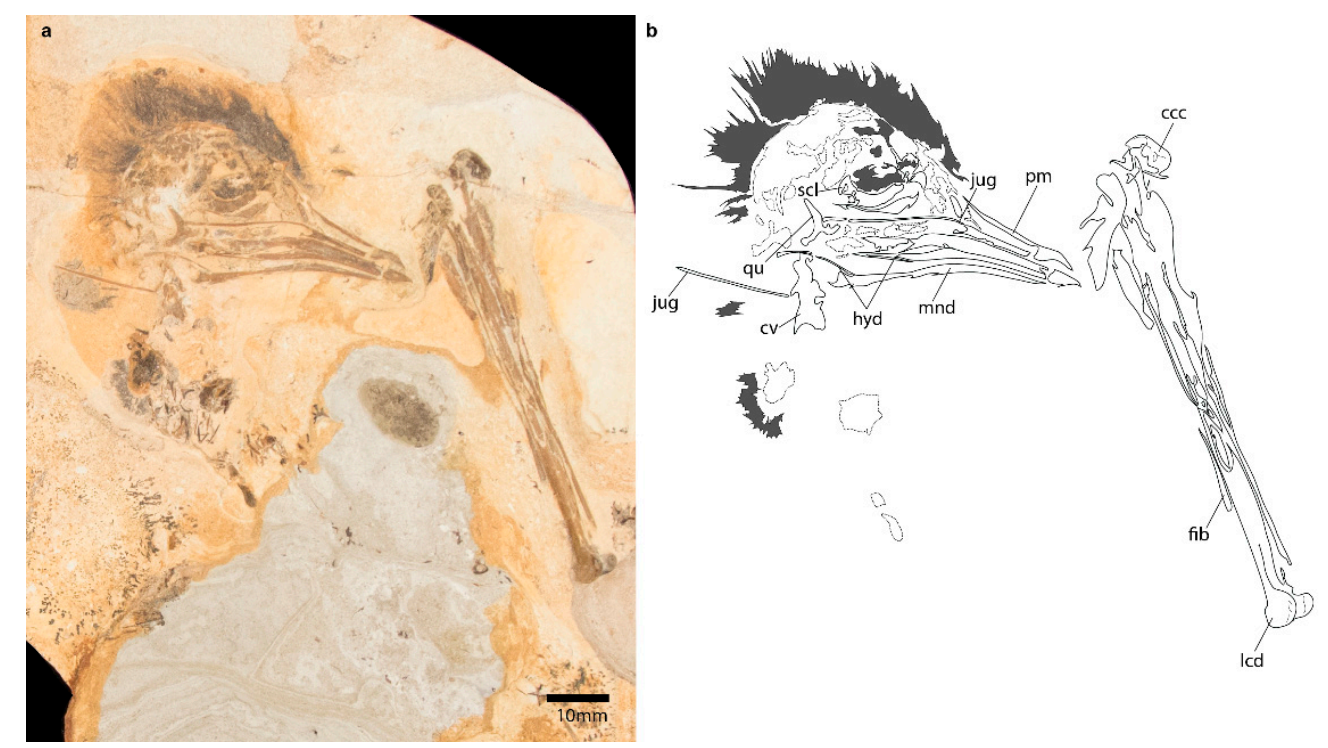

Figure 3. Photograph (a) and line drawing (b) of referred specimen of Pellornis mikkelseni, DK664. Soft tissue and plumage is filled in with gray. Dashed borders indicate bone that is extremely broken. Anatomical abbreviations: pm premaxilla, scl scleral ossicles, qu quadrate, jug jugal, mnd mandible, hyd hyoids, cv cervical vertebrae, ccc crista cnemialis cranialis, fib fibula, lcd lateral condyle (of tibiotarsus). 


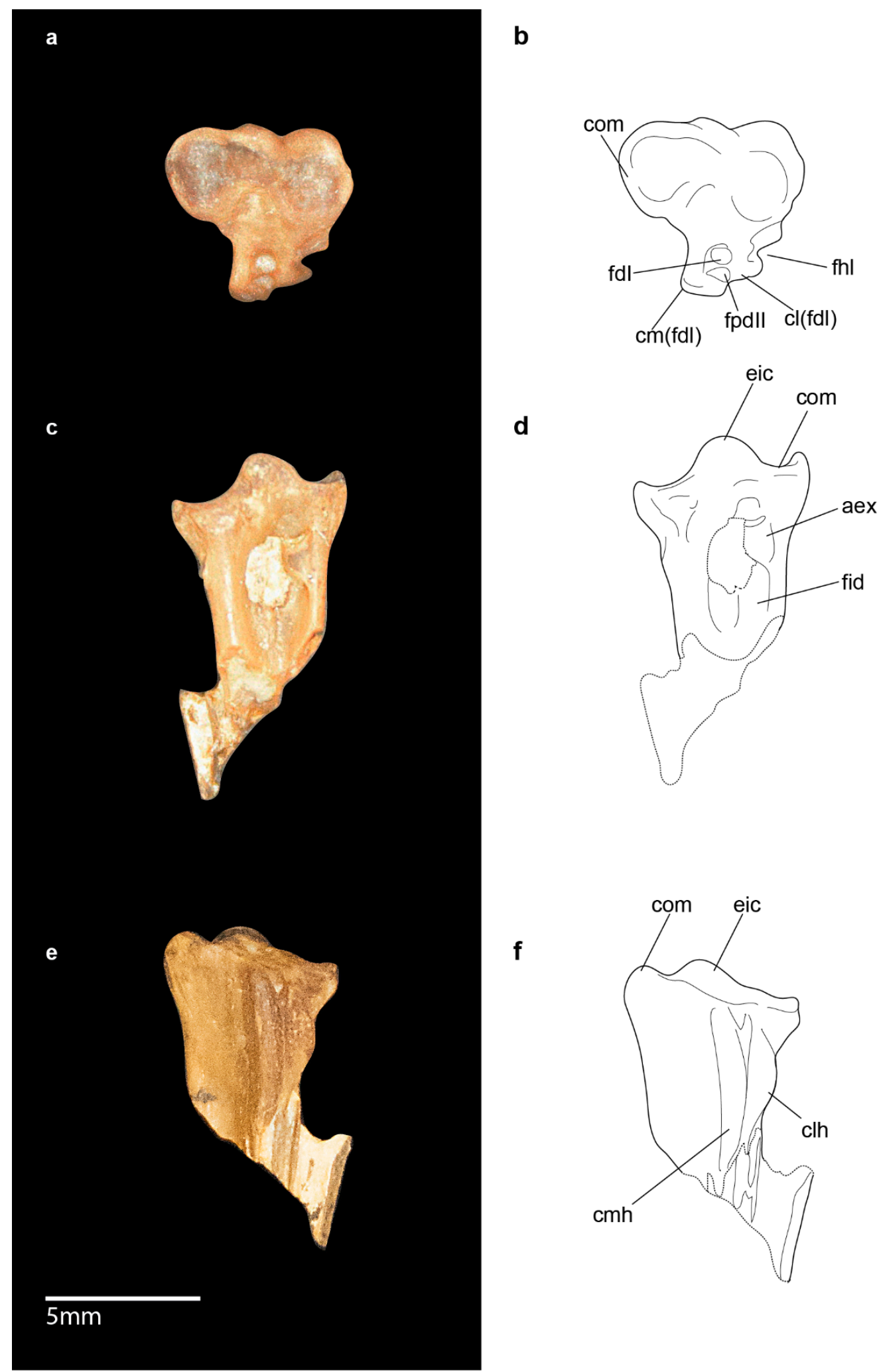

Figure 4. Photographs (a, c, e) and line drawings (b, d, f) of the right tarsometatarsus of referred Pellornis mikkelseni specimen, DK664 in proximal, dorsal, and ventral aspect. Anatomical abbreviations: eic eminentia intercotylaris, com cotyla medialis, aex arcus extensorius (ossified retinaculum), cl(fdl) crista lateralis flexoris digitorum longus, $\mathbf{c m}(\mathbf{f d l})$ crista medialis flexoris digitorum longus, fdl canal for $\mathrm{m}$. flexor digitorum longus, fpdII canal for $\mathrm{m}$. flexor perforates digiti II, fhl sulcus for $\mathrm{m}$. flexor hallucis longus, fid fossa infracotylaris dorsalis. The scale bar applies to all views. 


\subsubsection{Referred Specimen}

FUM 1681a, a partial postcranial skeleton of an adult individual preserved three-dimensionally on one slab (Figure 5).

Locality. Associated with ash layer +19 of the Silstrup Member, Fur Formation, Mors, northwestern Jutland, Denmark, latest Paleocene-earliest Eocene.

Measurements. See Table 2.
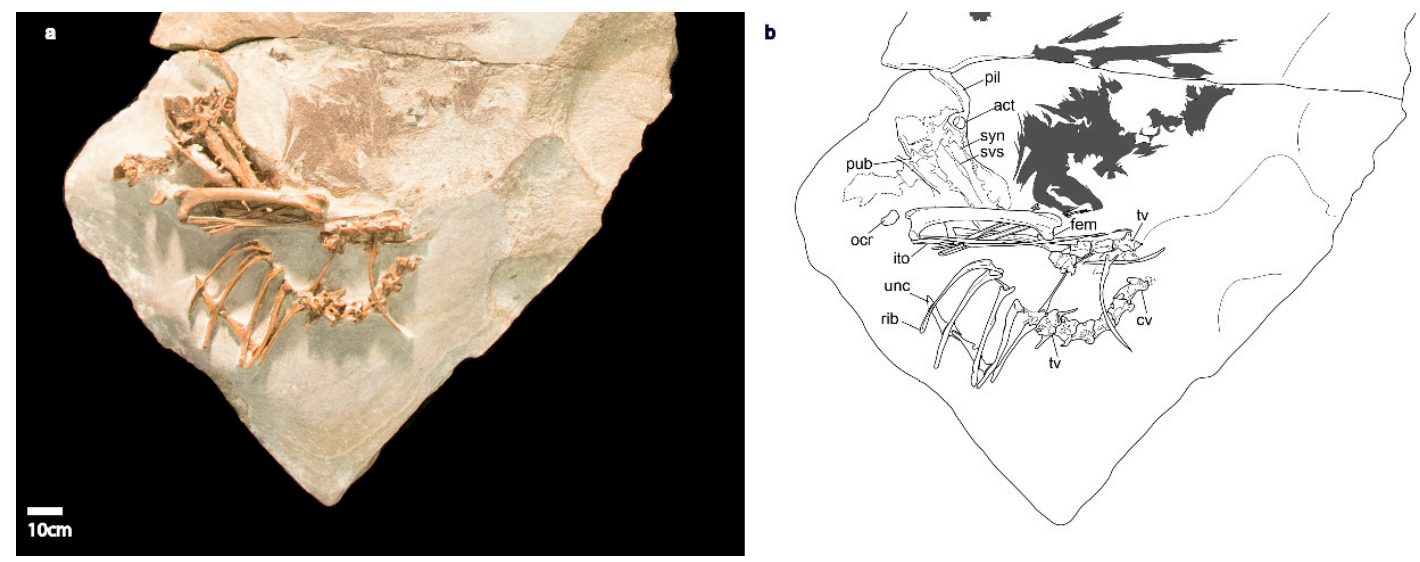

Figure 5. Photograph (a) and line drawing (b) of referred specimen of Pellornis mikkelseni, FUM 1681a. Soft tissue and plumage is filled in with gray. Dashed borders indicate bone that is extremely broken. Anatomical abbreviations: cv cervical vertebra, tv thoracic vertebra, rib rib, unc unfused uncinate process, syn synsacrum, svs sulcus ventralis synsacrum, ocr os carpi radiale, act acetabulum, pub pubis, pil postacetabular ilium, ito intratendinous ossification, fem femur.

\subsection{Emended Description and Remarks}

\subsubsection{Skull}

In MGUH 29278, the skull and mandible are preserved in left lateral aspect (Figures 1 and 2), and they are preserved in right lateral aspect in DK664 (Figure 3). The beak is delicately constructed, with a slender narial bar similar to most Rallidae, as opposed to the more robust narial bar of, e.g., Fulica americana and Heliornithidae. The rostral tips of the premaxilla and mandible of both MGUH 29278 and DK664 bear several minute neurovascular foramina, which are small in comparison to those of Rallidae and bear more of a resemblance to those of Heliornithidae. The jugal bar is exceptionally slender, even more so than that of Messelornis cristata [30]. The beak of the holotype specimen accounts for approximately $50 \%$ of overall skull length. In this way, the proportions are closer to those of Psophiidae than to those of most Rallidae which have longer beaks. The rostrum is fairly straight.

The cranium in both specimens appears caudally elongate, as in many Gruiformes. In ventral view, MGUH 29278 exhibits two narrow processes which appear to represent the left and right maxillopalatine processes, visible between the mandibles (Figures 1 and 2). These appear to contact at the midline, but this may be the product of taphonomic distortion. These processes take the form of a caudally projecting triangular point (exposed in ventral view) as in Heliornithidae and some Rallidae (e.g., Aramides ypecaha, F. americana), as opposed to the more rounded morphology in other Rallidae (e.g., Rallus crepitans, Amaurornis flavirostra, Gallinula chloropus). These processes are absent in Eurypyga helias. A very small and acuminate postorbital process is developed in P. mikkelseni as in M. cristata (Figures 1 and 2). It is not as robust or rounded as those of Gruidae. Additionally, a very modestly developed processus zygomaticus appears to be present, but bears no ossified aponeurosis zygomatica. It appears that fonticuli occipitales are absent from the caudal aspect of the skull as in 
crown Ralloidea and M. cristata, although much of the cranial anatomy cannot be observed given the orientation and crushing of the holotype skull.

In DK664 (Figure 3), a small broken piece of bone rostral to the sclerotic ring may represent the remains of the lacrimal. If this identification is correct, then a caudally projecting processus supraorbitales appears to be present, a character state present in all extant Gruiformes with the exception of Psophiidae (character 13 of Mayr and Clarke [44]). However, the identification of this broken element is uncertain, and it is possible it represents a vestige of the ectethmoid rather than the lacrimal.

The sclerotic ring in DK664 (Figure 3) appears to be dorsoventrally and lateromedially robust, although it is only partially preserved, precluding a reliable assessment of phylogenetically relevant morphology. Apparent melanin from the eye, preserved just above the remains of the sclerotic ring, was reported by a previous study [55]. The supraorbital crest and temporal fossa are too poorly preserved to confidently assess.

The otic process of the quadrate is narrow at its midshaft and widens markedly towards the otic end in both specimens (Figures 1-3). This bears more resemblance to the otic processes of Heliornithidae and most Rallidae than to the more robust otic processes of F. americana and Psophiidae. In the holotype specimen, there is a small pneumatic foramen located on the posterior face, between the two heads. This pneumatic foramen is not present in any of the Rallidae sampled here, but is present in Gruoidea. Only the condylus lateralis is exposed in both the holotype specimen and DK664 (Figure 3, preserved in medial view).

The medial surface of the left mandible of DK664 is visible despite the fossil being preserved in right lateral view, due to slight shearing of the specimen (Figure 3). The fenestrae rostralis mandibulae are thin and ovate in both MGUH 29278 and DK664. In DK664, the rostral portion of the mandible is recurved as in F. americana. A small opening with round edges is present at the posterior end of the right mandible in lateral view; however, it is likely that this opening is an artifact of damage. An apparent processus medialis of the left mandible appears to be low, comparable to the condition in Psophiidae and Rallidae. The caudal end of the mandible bears a narrow, dorsally projecting hook-like projection, comparable to the condition in Rallidae. In the holotype specimen, two rod-like elements are preserved adjacent to the mandible and appear to represent the remains of the hyoids (Figures 1 and 2). Thin remains of the hyoids have also been preserved between the rami of and just ventral to the mandibles in DK664 (Figure 3).

\subsubsection{Axial Skeleton}

The number of presacral vertebrae cannot be reliably assessed in any specimen of Pellornis mikkelseni. In MGUH 29278, poorly preserved remains of the atlas appear to be present just behind the posterior extent of the mandible (Figures 1 and 2). The other cervical vertebrae are similarly very poorly preserved in lateral aspect. A thoracic vertebra is preserved near the lateral margin of the right coracoid. The presence of costal processes cannot be reliably assessed. In DK664, the axis and one additional cervical vertebra are preserved (Figure 3). The axis apparently exhibits a modest, sub-trapezoidal processus spinosus and a prominent processus ventralis with a caudally angled apex, as in Rallidae. In FUM 1681a (Figure 5), at least ten vertebrae are preserved in total. Five of the caudal-most cervical vertebrae are preserved in articulation with the anterior-most thoracic vertebra in dorsolateral aspect. These are well preserved in three dimensions. The cervical vertebrae appear to become more elongate towards the cranial-most portion of the series, as in many Rallidae but unlike the condition in M. cristata. A cranio-caudally lengthened, modest processus spinosus is present on each cervical vertebra as in many Rallidae. The presence of costal processes cannot be assessed due to obfuscation by matrix. The anterior-most thoracic vertebra bears a small free rib on each side. A subrectangular, prominent processus spinosus appears to be present. The transverse processes appear to be craniocaudally elongate as in considered Rallidae. Four visible thoracic vertebrae appear to be heterocoelous. The centra are preserved in ventral aspect in FUM 1681a; they are dorsoventrally compressed and are saddle-shaped on both ends. The thoracic vertebrae are cylindrical with rounded 
ventral surfaces as opposed to those in Ralloidea in which the ventral surface is wasted down to a sharp keel. Although a complete thoracic series is not preserved in FUM 1681a, the presence of a notarium can be ruled out due to complete separation of the caudal thoracic vertebrae.

The sternum exhibits a robust carina and appears to have tapered caudally, as in many Rallidae (Figure 1). Two sets of caudal incisurae are present, as in Messelornis but unlike most Ralloidea. In FUM 1681a, as in other Gruiformes, the ribs bear unfused uncinate processes (Figure 5). The ribs are robust relative to the size of the femur; the femur is comparable in length to those of small rallids (e.g., Amaurornis), but the ribs are much closer in depth to those of larger rallids (e.g., F. americana). The ribs lack pneumatic foramina between the tuberculum and the capitulum. Such foramina are absent in Gruoidea and variable in Ralloidea.

\subsubsection{Pectoral Girdle}

In the holotype specimen, the furcula appears mediolaterally more robust than that of many extant members of Ralloidea and is more similar to that of Messelornis as mentioned in Bertelli et al. [35] (see Figure 1). Other features of this element are difficult to assess due to obfuscation by the bones of the left wing. The right and left coracoid are both preserved in dorsal aspect. The right coracoid exhibits a cup-like cotyla scapularis, as in M. cristata. As mentioned by Bertelli et al. [35], a small opening sternal to the processus procoracoideus exists, but it is difficult to determine whether it represents the foramina $n$. supracoracoideus or is merely the result of preparation damage. The processus procoracoideus of the right coracoid appears more similar to that of Rallidae than to the more prominent processus of M. cristata or Messelornis nearctica. The processus acrocoracoideus of the left coracoid has been sheared, but the facies articularis humeralis appears to have been proximodistally elongate and mediolaterally prominent as in Rallidae.

The right scapula is preserved in medial view. As previously noted [35], a portion of the blade of the left scapula is also present. The right scapula is elongate and slender but appears to be more mediolaterally robust than in extant Rallidae. This is similar to the condition in M. cristata, although the scapula of Pellornis does not taper as abruptly towards the caudal apex. A tubercle is present on the costal surface towards the cranial terminus, as in M. cristata. Mayr [56] considered this character a synapomorphy of Rallidae, though Ksepka [57] noted a wider distribution. In this study, we consider this feature a synapomorphy of total group Ralloidea.

\subsubsection{Forelimb}

The left humerus of the holotype is preserved in cranial aspect and the right humerus is present in caudal aspect. The crista deltopectoralis is not very prominent compared to most extant Ralloidea and M. nearctica. The distal portion of the crista bicipitalis is similarly less mediolaterally robust than the condition in Ralloidea or M. cristata, and in this way is more similar to the condition in M. nearctica. Preparation of the new slab of MGUH 29278 has exposed the distal extremity of the right humerus of Pellornis. The processus supracondylaris dorsalis is truncate and rounded, as in M. cristata and M. nearctica. The ulnae and radii were previously described [35]; however, we observe that the ulna extends under the skull on the newly prepared block. Poor preservation prevents the definitive identification of important anatomical features. The ulna, radius, carpometacarpus, and phalanges were previously described in the holotype [35]. In FUM 1681a, an isolated bone is present, broken on one side and preserved just above the cranial end of the crista trochanteris (Figure 5). This appears to represent the radiale.

\subsubsection{Pelvic Girdle}

The pelvis is preserved in dorsal view in the holotype specimen (Figure 1), with the right preacetabular ilium preserved in medioventral aspect due to disarticulation (Figure 2). The pelvis in the holotype demonstrates that the preacetabular ilii were not fused to the synsacrum as in M. nearctica and M. cristata, unlike the condition in Rallidae. The crista spinosa synsacri is visible. 
The synsacrum exhibits a few small foramina intertransversaria; however, these are not nearly as extensive as in Charadriiformes or Eurypygidae and are generally comparable to the condition in Rallidae. The number of vertebrae ankylosed into the synsacrum cannot be reliably assessed, as the preservation of the holotype synsacrum makes this difficult to distinguish. The remains of some caudal vertebrae as well as the pygostyle are preserved along the caudal end of the synsacrum.

In FUM 1681a, the pelvis is well preserved in ventral view. As in the holotype, it is clear that the alae preacetabularis ilii were not fused to the synsacrum. The anterior-most processes costales of the preacetabular vertebrae are cranially oriented. A deep sulcus ventralis synsacri is present. The large and prominent cristae iliacae are preserved three-dimensionally and are hardly displaced from their in vivo position. They are mediolaterally broad as in Psophiidae. The left acetabulum is visible in medial view and is undisplaced. It is large like that of many Rallidae. The right acetabular region is somewhat damaged and rotated such that the acetabulum faces ventrolaterally. The processes costales of two acetabular vertebrae are strut-like and extend to the margin of the acetabulum. This suggests that deep fossae renales were present, as in Gruiformes.

\subsubsection{Hindlimb}

In MGUH 29278, the left femur and tibiotarsus are preserved in lateral aspect (Figure 1). In the well-preserved femur of FUM 1681a, the degree of cranial extension of the crista trochanteris is essentially indistinguishable from that exhibited by Rallidae and M. cristata, but greatly exceeds that of Heliornithidae (Figure 5). The femur exhibits no pneumatic foramen on the craniolateral side of the proximal end (Figure 5). The femur's proximal portion and trochanteric region is distinctly flattened, even more so than that of Heliornithidae. The femoral head appears proximodistally compressed and the fovea ligamentum capitis appears proximally oriented, as in Rallidae. The trochanteric region is more laterally splayed than that of Rallidae. The medial and lateral crests are of essentially equal height and are fairly prominent. They are distinctly more prominent than those of Heliornis fulica, which border a fairly deep patellar sulcus.

In the holotype specimen, the crista cnemialis lateralis of the left tibiotarsus appears truncate as in M. cristata, and its apex is not sharply defined (Figure 1). Gruoidea exhibit an even more laterally and proximodistally prominent crista, which is also notably decurved. The cranial portion of the fibular head of the holotype specimen is decurved and not very prominent, which is in contrast to the tubercular, proximally oriented cranial portion of the fibular head of Rallidae. In this way, it appears to be more similar to the fibular head in Gruoidea. The caudal portion of the fibular head appears to have a sigmoidal morphology that is not present in extant Gruiformes. In DK664, the right tibiotarsus is well preserved in craniolateral view, and despite some crushing is preserved three-dimensionally (Figure 3). It is elongate and slender and is slightly shorter than that of Rallidae. A very prominent crista cnemialis cranialis is present as is typical for Rallidae. It appears to have been less cranially extensive than that of $M$. cristata and more proximally extensive than that of $M$. nearctica. Although the apex is partially obscured by matrix, it seems to have been blunted with rounded corners as in Rallidae. Some Rallidae such as Aramides saracura [44] exhibit a prominent tubercle laterodistal to the pons supratendineus. This tubercle is absent in P. mikkelseni. Several thin ossified tendons lie along the length of the element. The medial condyle is markedly smaller than the lateral condyle. A thin splint of the fibula is preserved alongside the tibiotarsus. The distal rim of the condylus medialis is pressed into the matrix and obscured, precluding assessment of whether the distal rim is distinctly notched, although further mechanical preparation could potentially expose this feature.

In DK664, the proximal portion of the right tarsometatarsus resembles Rallidae and M. cristata in possessing a strongly proximally projected eminentia intercotylaris. The cotyla medialis terminates slightly more proximally than the cotyla lateralis, although this difference is not as drastic as that exhibited in Rallidae. This condition is also present in M. cristata. The medial margin of the cotyla medialis appears to be prominent and form a robust, proximally oriented lip as in many Rallidae. The fossa infracotylaris dorsalis is dorso-plantarly deep and proximally broad as in Rallidae, 
and an ossified retinaculum is present as in Messelornis and most extant Ralloidea. The crista lateralis flexoris digitorum longus is not more plantarly prominent or cranio-caudally elongate than the crista medialis flexoris digitorum longus. The cristae form one clearly enclosed canal and a second passage that was either an enclosed canal or a deep and very nearly enclosed sulcus. Based on position and comparison to extant Rallidae, we interpret these as the pathways for the musculus flexor digitorum longus and for the tendons of musculus flexor perforatus digiti 2 and musculus flexor perforans et perforatus digiti 2 (Figure 4). A sulcus for the musculus flexor hallucis longus appears to be present. This is most similar to the condition in Itardiornis hessae [34].

\subsubsection{Intratendinous Ossifications}

In the holotype specimen and FUM 1681a, splint-like intratendinous ossifications are present adjacent to both the forelimb and hindlimb bones (Figure 5). Intratendinous ossifications are present along the carpometacarpus and phalanx proximalis digiti majoris of the holotype specimen, with one markedly more elongate ossified tendon located along the cranial margin of the distal end of the carpometacarpus (Figure 1). The ossified tendon is approximately one-third the length of the carpometacarpus, although this may not represent its true length as Bertelli et al. [35] note that it is likely incomplete. Presence of such an elongate ossified tendon along the carpometacarpus is also observed in many M. cristata specimens and extant members of Gruidae. In FUM 1681a, a mass of strongly developed ossified tendons are present along the medial edge of the femur and just distal to it; whether these were associated with the femur in vivo is difficult to assess in this disarticulated specimen. The ossifications are elongate and extend along the length of the femur. Intratendinous ossifications that appear thinner and more elongate than those of the forelimbs are arranged in a fan-like shape along the cranial and caudal margins of the distal shaft of the tibiotarsus. These have been tentatively ascribed to the tendons of the $\mathrm{m}$. gastrocnemius [35]. Long ossified tendons along the tibiotarsus are also present in Messelornis nearctica, in which they are similarly extensive but distinctly more robust [28].

\subsubsection{Plumage}

Contour feathers are preserved in the holotype specimen and DK664 (Figures 1-3). In FUM 1681a, a single, elongate tail feather is preserved alongside the skeleton, with several other feather impressions most likely representing contour feathers (Figure 5). Some of these feathers are well preserved, enabling the contact between individual barbs and the rachis to be ascertained. The tail feather has been imaged, and its melanosomes characterized in a previous study [58]. Time-of-flight secondary ion mass spectrometry (TOF-SIMS) and scanning electron microscopy (SEM) analysis suggested that the feathers would have been black-brown in color [58].

\subsection{Phylogenetic Results}

Unconstrained parsimony heuristic analysis resulted in 34,720 most parsimonious trees (MPTs) of 326 steps. This analysis recovered a large polytomy with all relationships within Gruiformes unresolved with the exception of Gruoidea, in which Parvigrus pohli was placed as the sister-taxon of Gruidae+Aramidae $(\mathrm{CI}=0.356, \mathrm{RI}=0.705, \mathrm{RC}=0.251, \mathrm{HI}=0.644)$. Our analysis applying the molecular scaffold of Prum et al. [3] recovered 20,160 MPTs of 334 steps (Figure 6b; CI = 0.347, $\mathrm{RI}=0.693, \mathrm{RC}=0.241, \mathrm{HI}=0.653$ ) with a similar lack of resolution. When the fossil taxon Australlus was removed, we recovered Messelornis, Pellornis mikkelseni, Itardornis hessae and Songzia acutunguis in a polytomy just outside of crown Ralloidea (unconstrained analysis; MPTs $=130$, steps $=326, \mathrm{CI}=0.356$, $\mathrm{RI}=0.703, \mathrm{RC}=0.250, \mathrm{HI}=0.644$ ) or in a larger polytomy including Heliornis, Sarothrura and Rallidae (constrained analysis; $\mathrm{MPTs}=78$, steps $=334, \mathrm{CI}=0.347, \mathrm{RI}=0.691, \mathrm{RC}=0.240, \mathrm{HI}=0.653$ ).

When both Australlus and I. hessae were excluded, unconstrained heuristic searches recovered a clade containing Messelornis, Pellornis and Songzia as the sister-group of crown Ralloidea (Figure 6a; $\mathrm{MPTs}=30$, steps $=325, \mathrm{CI}=0.357, \mathrm{RI}=0.701, \mathrm{RC}=0.250, \mathrm{HI}=0.643)$, and Saurothrura was placed 
as the sister-taxon of Rallidae. Constrained analysis again recovered a clade containing Messelornis, Pellornis and Songzia, and this group was placed within a polytomy comprising Heliornis, Sarothrura and Rallidae (Figure 6b; MPTs $=48$, steps $=333, \mathrm{CI}=0.348, \mathrm{RI}=0.690, \mathrm{RC}=0.240, \mathrm{HI}=0.652$ ). Synapomorphies of selected groups from these unconstrained and constrained analyses are reported in Table 4.
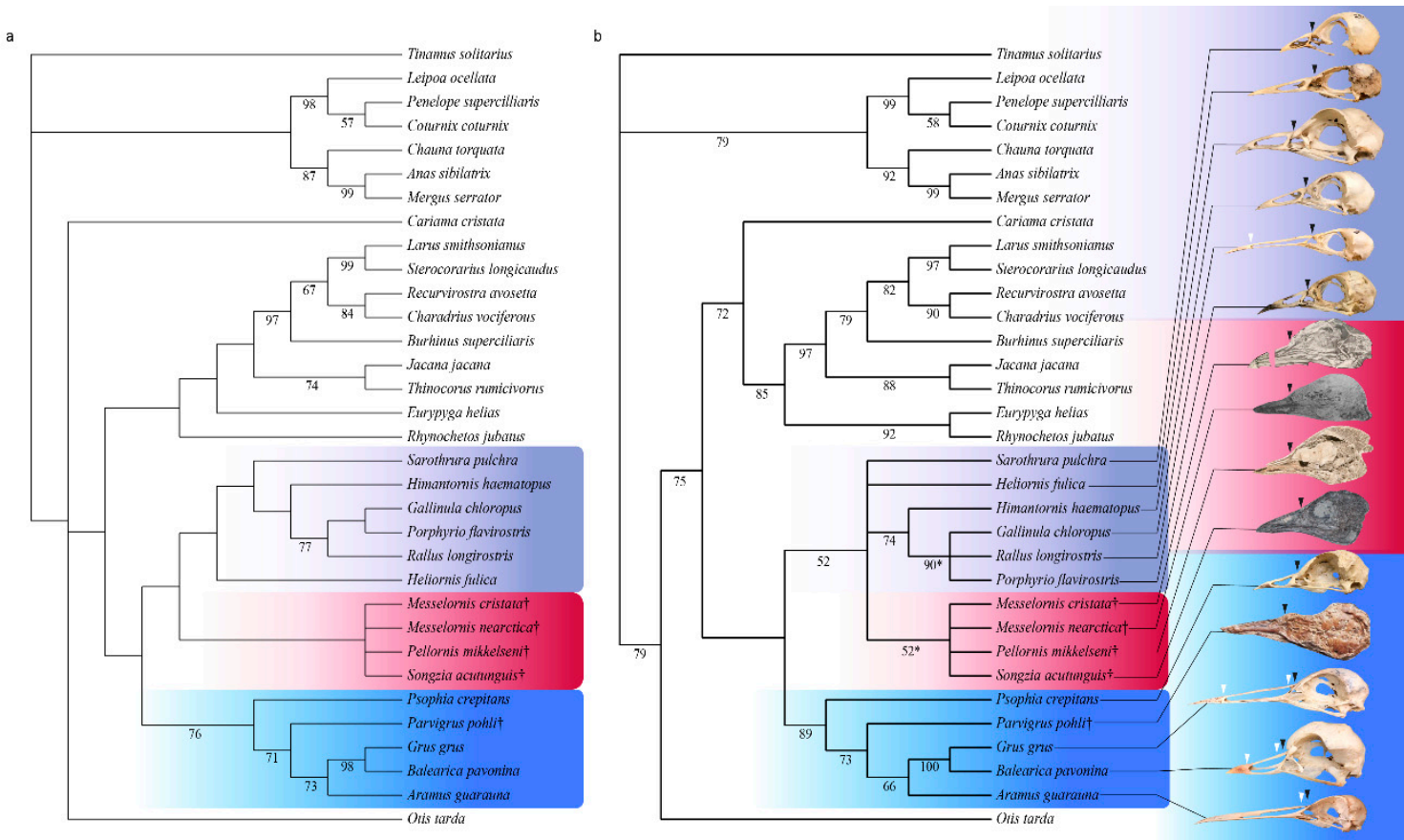

Figure 6. Strict consensus tree of $30 \mathrm{MPTs}$ recovered from unconstrained heuristic parsimony analysis $(\mathbf{a}$, steps $=325, \mathrm{CI}=0.357, \mathrm{RI}=0.701, \mathrm{RC}=0.250, \mathrm{HI}=0.643)$ and strict consensus tree of $48 \mathrm{MPTs}$ recovered using the Prum et al. [3] tree as a molecular backbone constraint ( $b$, steps $=333, \mathrm{CI}=0.348$, $\mathrm{RI}=0.690, \mathrm{RC}=0.240, \mathrm{HI}=0.652)$. Crown Ralloidea are highlighted in violet, crown Gruoidea are highlighted in blue, and included extinct ralloid taxa are highlighted in crimson (Messelornithidae and Songzia acutunguis). All extinct taxa are denoted with daggers. Bootstrap support values greater than $50 \%$ are denoted below branches. Black arrows in extant skulls denote the craniofacial hinge, with white arrows representing additional bending axes along the dorsal bar following Zusi [59]. Black arrows in fossils represent the level of the craniofacial hinge as bending zones cannot be determined in fossils. Photographs of skulls from top to bottom: Sarothrura pulchra USNM 291778, Heliornis fulica USNM 19159, Himantornis haematopus USNM 318591, Gallinula chloropus USNM 603455, Rallus longirostris USNM 501940, Porphyrio flavirostris USNM 623070, Messelornis cristata (composite photo made from Tafel III:8 and Tafel IV:10) [30], Messelornis nearctica [24] Pellornis mikkelseni MGUH 29278, Songzia acutunguis [36], Psophia crepitans USNM 429974, Parvigrus pohli [46,47], Grus grus USNM 610382, Balearica pavonina USNM 320869, Aramus guarana USNM 612025. 
Table 4. Optimized synapomorphies of selected groups recovered through unconstrained and constrained analyses employing the molecular backbone constraint of Prum et al. [3] with Australlus and Itardiornis excluded. Superscripts of 1 denote synapomorphies with $\mathrm{CI}=1.0$. Asterisks indicate unambiguous synapomorphies. Dashes indicate groups that were unresolved in strict consensus trees, although all optimized synapomorphies are reported for the unresolved group containing Pellornis, Messelornis and Songzia.

\begin{tabular}{|c|c|c|}
\hline Group Name & Unconstrained (Tree 1) & Prum et al. [3] Constraint \\
\hline Gruiformes (including extinct taxa) & $\begin{array}{c}5(1), 10(1)^{1}, 30(1), 45(1), 46(0), 70(0), 81(1) \\
98(1), 99(1)\end{array}$ & $\begin{array}{c}10(1)^{1}, 30(1), 45(1), 46(0), 51(1), 96(0), 98(0), \\
99(1)\end{array}$ \\
\hline Gruoidea (including P. pohli) & $\begin{array}{c}4(0), 33(2), 39(1), 48(1) * * 49(1), 51(1) *, 56(1) \\
1,59(2) * * 77(1), 82(0), 86(1)^{1} \\
87(1)^{*}\end{array}$ & $\begin{array}{c}33(2), 34(1), 39(1), 48(1)^{*}, 49(1), \\
54(0)^{*}, 56(1)^{1}, 59(2)^{*}, 77(1), 86(1)^{1}, 87(1)^{*}\end{array}$ \\
\hline P. pohli + (Aramidae + Gruidae) & $\begin{array}{c}1(1) *, 19(1), 22(1), 31(1), 45(0), 53(1), 65(0) \\
70(1), 72(1) 1,84(0)\end{array}$ & $\begin{array}{c}1(1) *, 19(1), 22(1), 31(1), 45(0), 53(1), 65(0), \\
70(1), 72(1) 1,84(0)\end{array}$ \\
\hline Aramidae + Gruidae & $69(1) *, 91(1) *$ & $69(1) *, 91(1) *$ \\
\hline Gruidae & $\begin{array}{c}12(0) *, 32(0) *, 42(1)^{1 *}, 55(2) *, 84(1) *, 92(0) \\
*, 96(1) *\end{array}$ & $\begin{array}{c}12(0)^{*}, 32(0) *, 42(1)^{1 *}, 55(2) * \\
84(1)^{*}, 92(0)^{*}, 96(1)^{*}\end{array}$ \\
\hline $\begin{array}{c}\text { Pellornis + Messelornis + Songzia } \\
\text { + Ralloidea }\end{array}$ & $\begin{array}{c}34(0), 41(1), 62(0), 67(1), 80(1){ }^{1}, 88(1), 91(1) \\
92(0), 93(1)^{1}\end{array}$ & $\begin{array}{c}41(1), 62(0), 67(1), 80(1){ }^{1}, 88(1), 91(1), 92(0), \\
93(1){ }^{1}\end{array}$ \\
\hline Ralloidea & $2(0), 79(0) *, 90(1) *$ & $2(0), 57(1) *, 79(0) *, 90(1) *$ \\
\hline Sarothruridae + Rallidae & $51(1) *, 57(1) *, 82(0), 101(1)$ & - \\
\hline Rallidae & $4(0) *, 54(1) *, 77(1) *, 91(0)$ & $77(1) *, 91(0)$ \\
\hline $\begin{array}{l}\text { R. longisrostris }+(\text { G. chloropus } \\
+ \text { P. flavirostris })\end{array}$ & $23(0) *, 38(1) *, 97(1) *, 101(0) *$ & $23(0) *, 38(1) *, 97(1) *$ \\
\hline
\end{tabular}

\subsection{Body Size}

Our mean body size estimate for FUM 1681a, based on the predictive equations of Field et al. [51], was $222 \mathrm{~g}(95 \% \mathrm{PI}+/-133.28 \mathrm{~g})$. This mean estimate places Pellornis mikkelseni within the general body size range of moderately large extant rails (e.g., buff-banded rail, Hypotaenidea philippensis) [60], but considerably below the size of the largest volant rails (e.g., Aramides ypecaha, 600-800g) and nearly ten times the size of the smallest extant rails and flufftails (e.g., Porzana flaviventer, Sarothrura insularis, $\sim 25 \mathrm{~g}$ ). The largest extant rails are all flightless, at least as adults (e.g., Fulica gigantean, $~ 2700 \mathrm{~g}$ ) [60].

\section{Discussion}

\subsection{Phylogenetic Position of Pellornis, Songzia and Messelornithidae}

Our results corroborate the placement of Pellornis mikkelseni as a crown gruiform more closely related to Ralloidea than to Gruoidea [34]. Results obtained using the molecular backbone constraint [3] are consistent with those of Bertelli et al. [35] in placing P. mikkelseni within a clade containing Messelornis cristata $(56 \%)$. However, we were unable to resolve whether the Pellornis+Messelornis+Songzia clade represents the sister-taxon of crown Ralloidea or is nested within this clade. The former hypothesis is supported by the unconstrained analyses, but when extant taxa are constrained to match recent molecular results this portion of the tree is incompletely resolved (Figure 6).

Two ambiguous synapomorphies within the pelvis with $\mathrm{CI}=1.0$ and seven ambiguous synapomorphies in the thoracic vertebrae, scapula, humerus, and tarsometatarsus with $\mathrm{CI}<1.0$ were recovered for the most exclusive clade uniting Pellornis+Messelornis+Songzia and crown Ralloidea, but due to varying preservation not all of these features can be evaluated in all fossil taxa. Both our unconstrained analysis and our analysis employing the molecular backbone constraint recovered one synapomorphy that can be observed as present in Pellornis, Messelornis and Songzia: presence of a proximal humeral shaft with a triangular cross-section (67:1). One ambiguous synapomorphy with $\mathrm{CI}=1.0$ can be observed in Pellornis and Messelornis: a furrow or canal for the tendon of musculus flexor perforatus digiti II that is marked and laterally bordered by a proximodistally long and plantarly 
protruding crista lateralis (93:1). Three synapomorphies can be observed in Pellornis and M. cristata (but not M. nearctica): presence of a tubercle on the costal surface of the cranial end of the scapula (41:1), presence of an ossified retinaculum extensorium tarsometatarsi (88:1), and enclosure of the tendon of the musculus flexor digitorum longus in a bony canal in the hypotarsus (91:1). One synapomorphy can be observed in Messelornis and Songzia: plantar deflection and proximal elevation of trochlea metatarsi II (92:0). Finally, one synapomorphy can only be observed in M. cristata: lack of foramina pneumatica at the bottom of the fossa pneumotricipitalis of the humerus (62:0). Unconstrained analyses recovered an additional synapomorphy present in Pellornis, M. cristata and Songzia: absence of a notarium (34:0).

For the clade containing Pellornis, Messelornis and Songzia, three synapomorphies were recovered in both the unconstrained and constrained analyses: presence of four notches or fenestrae in the caudal margin of the sternum (unambiguous, 59:0), lack of fusion of the iliac blades to the synsacrum (78:1, uncertain in Songzia), and lack of a raised muscle attachment scar for the musculus latissimus dorsi on the humerus (66:0, uncertain in Messelornis). Unconstrained analysis recovered an additional synapomorphy for this clade that can only be evaluated in M. cristata and Songzia: presence of a prominent and blade-like spina externa rostri of the sternum (54:1). Constrained analysis recovered one additional synapomorphy: a wide sternum (51:0, uncertain in Pellornis due to preservation). The presence of a straight, thin and elongate processus terminalis of the ischium that is caudally tapered to a subrectangular terminus (82:1) is potentially an additional synapomorphy for this clade, though it would have to be reversed in at least one taxon. This morphology is observed in Songzia and M. nearctica, but the process is much wider in M. cristata and cannot be observed in Pellornis.

\subsection{Possible Monophyly of a Pellornis + Messelornis Clade}

Our analyses demonstrate that the inferred monophyly of Messelornithidae is sensitive to the placement of extant taxa. The grouping of extinct ralloid taxa received low support across our analyses $(<50 \%$ bootstrap in unconstrained analysis, $52 \%$ bootstrap for placement of all extinct ralloids with the exception of $S$. acutunguis in constrained analysis). Bertelli et al. [35] likewise reported weak support for a P. mikkelseni + M. cristata sister-group (38\% jackknife support), and Wang et al. [36] recovered low support for all placements of P. mikkelseni, M. cristata and S. acutunguis ( $<50 \%$ bootstrap support). These results suggest that despite relatively good fossil material, the relationships of early gruiform taxa remain difficult to resolve. This difficulty may be the result of relatively rapid phylogenetic divergences within Gruiformes in the early Paleogene, as has been suggested in numerous avian phylogenetic studies [1-3,7,61-63].

As in previous work, we infer that Pellornis mikkelseni is closely related to Messelornithidae. Bertelli et al. [35] reported two unambiguous synapomorphies for Messelornithidae, including Pellornis. However, one of these, possession of a broad and truncate sternum, was emended in our study to be unscorable for P. mikkelseni due to diagenetic deformation. Nonetheless, P. mikkelseni and Messelornis share a highly similar overall appearance: our scorings are identical for all characters for which P. mikkelseni, M. cristata and/or M. nearctica taxa can be scored with the exception of the morphology of the nares as discussed below.

Further study is needed to attain more confident placement of the enigmatic extinct taxon Songzia. Although we recovered this taxon within the same clade as Messelornis and Pellornis, the absence of intratendinous ossifications, strongly bowed hallux, and lack of an alular claw are unusual features that clearly set this taxon apart from "typical" messelornithids. Although our study suggests that the placement of Songzia within Messelornithidae cannot be ruled out, we consider this taxon to be in need of further study.

The most pronounced difference between P. mikkelseni, Messelornis and Songzia regards the conformation of the nares and zona flexoria craniofacialis. P. mikkelseni clearly exhibits schizorhinal nares [sensu 59], in which the caudal border of the narial opening is slit-like and extends beyond the zona flexoria craniofacialis. In contrast, the narial openings of Messelornis nearctica and Songzia have a wider and more rounded caudal border and terminate rostral to the zona flexoria craniofacialis $[24,34,36]$. 
The nares of Messelornis cristata are slit-like along the caudal margin but terminate rostral to the zona flexoria craniofacialis [30]. This raises the question of whether schizorhiny might be ancestral within Messelornithidae, and thus potentially within Gruiformes as a whole. Although schizorhiny is widespread in Gruoidea (present in all Aramidae, Gruidae, and the fossil Parvigrus), the deeply diverging Psophiidae, which are the sister taxon to all other extant Gruoidea (e.g., Prum et al. [3]), exhibit holorhinal nares with rounded caudal margins. This is also true of the Heliornithidae and Sarothruridae, which are the sister taxa to all other extant Ralloidea (e.g., Prum et al. [3]). The phylogenetic distribution of this feature is further complicated by the fact that the higher-order placement of Gruiformes within Neoaves remains inconsistent across recent cutting-edge phylogenomic studies, leaving it unclear whether the extant sister-taxon of Gruiformes might be a clade with widespread schizorhiny such as Charadriiformes [2], a holorhinal clade such as Musophagiformes [64], or even a large assemblage of major clades further obscuring the ancestral condition [3].

Regardless of whether schizorhiny is ancestral for Ralloidea or apomorphic for Pellornis, the presence of this morphology in P. mikkelseni suggests that it may have differed from the roughly contemporary Messelornis in feeding strategy. All schizorhinal birds show some degree of rhynchokinesis, influencing the function of the bill, with implications for feeding ecology [59]. Hesse 1990 [30] hypothesized that the bill of M. cristata exhibits double rhynchokinesis, and found that the bill of M. neartica was at least amphikinetic (Figure 6). The holorhinal nares and narial bar morphology of Songzia acutunguis suggest that its bill was either prokinetic or amphikinetic, as in extant Ralloidea. The schizorhinal nares of P. mikkelseni show that its bill was rhynchokinetic, although it is unclear whether P. mikkelseni would have exhibited double rhynchokinesis or proximal rhynchokinesis. The schizorhinal morphology of P. mikkelseni thus suggest that ecological differences between these taxa may be more extensive than the locomotor differences suggested by Bertelli et al. [35]. Additional specimens of P. mikkelseni exhibiting gut contents may be necessary to fully understand implications for feeding and the type of rhynchokinesis present.

\subsection{Divergence Times of Gruiformes}

Our placement of P. mikkelseni within crown Gruiformes suggests that some recent high profile phylogenomic divergence time analyses have underestimated the age of crown Gruiformes $[1,3,5]$. The occurrence of a strongly supported total-group ralloid in the latest Paleocene/earliest Eocene illustrates that the deepest divergence within crown Gruiformes must be at least Paleocene in age, consistent with a rapid early radiation of predominantly non-arboreal Neoaves following the end-Cretaceous mass extinction $[4,7,20,65]$.

Although the early fossil record of crown Ralloidea is currently sparse, some additional fossil material is consistent with an early Paleogene radiation of Ralloidea, including the two oldest well-represented exemplars of total-clade Rallidae, Belgirallus oligocaenus and B. minutus [56,66,67], from the earliest Oligocene of Europe. The age of these fossils suggests that the divergence of Rallidae from the rest of Ralloidea likely occurred in the Eocene. Incorporating Pellornis mikkelseni and additional ralloid fossils into future investigations of gruiform divergence times may shed additional light on the age of the crown gruiform radiation. However, close consideration of the effect of data type on divergence time model misspecification $[4,64]$, and possibly development of sophisticated time-heterogeneous divergence time models [6,7] may be necessary to confidently assess the age of crown Gruiformes and the remainder of the extant neoavian radiation.

Supplementary Materials: All data has been made publicly available on Morphobank [50] under Project 3456 (http://morphobank.org/permalink/?P3456). Character descriptions are provided in the Appendix A.

Author Contributions: Conceptualization, all authors; Methodology, all authors; Software, G.M. and D.T.K.; Validation, all authors; Formal Analysis, G.M.; Investigation, all authors; Resources, all authors; Data Curation, G.M.; Writing-Original Draft Preparation, G.M.; Writing—Review and Editing, all authors; Visualization, G.M. and D.J.F.; Supervision, D.J.F. and G.M.; Project Administration, D.J.F. and G.M.; Funding Acquisition, G.M and D.T.K. 
Funding: This project was supported by a National Science Foundation GRFP award (to G. M., grant number DGE-16-4486) and a National Science Foundation DEB award (to D.T.K., grant number 1655736).

Acknowledgments: We are greatly appreciative of the collections staff of the Geologisk Museum at the University of Copenhagen, and Museum Salling, especially Gilles Cuny and Bo Schultz, for facilitating loaning and study of the Pellornis specimens. We are additionally indebted to Bo Schultz for detailed information on the stratigraphic provenance of these specimens. We sincerely thank the collections staff of the Yale Peabody Museum (Kristof Zyskowski), American Museum of Natural History (Joel Cracraft, George Barrowclough, Brian Smith, Thomas Trombone, and Paul Sweet), United States National Museum (Helen James and Christopher Milensky) and Texas Memorial Museum for allowing us to examine comparative material for this study. We thank Joel Cracraft and Julia Clarke for their valuable discussions and advice, and Jakob Vinther for logistical help and support. We are very grateful to Marilyn Fox (Yale Peabody Museum) for her expert mechanical preparation of these fossils. Last, we thank two anonymous reviewers for comments that improved this manuscript.

Conflicts of Interest: The authors declare no conflict of interest.

\section{Appendix A}

Character matrix (after Mayr and Clarke [44] and Bertelli et al. [35]). Characters added by Bertelli et al. [35] are indicated by an asterisk, two asterisks denote characters added for the present study. Daggers denote characters with new scorings for P. mikkelseni or scorings for this taxon which differ from those of Bertelli et al. [35]. All scorings of P. mikkelseni are detailed in the character descriptions. Citations are only provided for newly added characters. The data matrix is publicly available on Morphobank [50] under Project 3456 (http://morphobank.org/permalink/?P3456).

1.† Nostrils: schizorhinal, i.e., caudal margin slit-like and extending caudally to naso-frontal hinge: no (0); yes (1). P. mikkelseni was scored as (1) based on MGUH 29278.

$2^{* *}+$. Nostrils: Nares extend caudally beyond rostral border of antorbital fenestra: no (0); yes (1). P. mikkelseni was scored as (1) based on MGUH 29278.

3. Palate, processus maxillopalatini of ossa maxillaria fused along their midline: no (0); yes (1).

4. Lacrimal, well developed descending process, which touches or nearly touches the jugal bar: yes (0); no (1).

5. Lacrimal, caudally projecting processus supraorbitales: absent (0); present (1); laterally projected (2). 6*. Ectethmoid: greatly reduced or lost: no (0); yes (1).

7. Palatine, well developed crista ventralis: absent (0); present (1).

8. Palatine, pars lateralis: absent or very small (0); present and well developed (1).

9. Palatine, completely fused along midline: no (0); yes (1).

10*. Pterygoid, rostral end markedly widened: no (0); yes (1).

11. Vomers, caudal ends not fused, more or less deeply cleft: yes (0); no (1).

12. Vomers mediolaterally wide: yes (0); no (1).

13. Vomers forming a midline, narrow, and dorsoventrally high lamella: no (0); yes (1).

14. Basipterygoid articulation in adulthood: present (0); absent (1).

15. Basipterygoid process, facet for articulation with pterygoid large and ovoid: no (0); yes (1).

16. Frontal, dorsal surface with marked depressions for supraorbital salt glands: absent (0); present (1).

17. Cranium, basiparasphenoid plate inflated, rounded, broad, and meeting the parasphenoid rostrum at a very acute angle; ostia canalis carotici et opthalmici externi situated in a well- marked depression: no (0); yes (1).

$18^{*}$. Laterosphenoid, large opening dorsocaudally of foramen n. maxillomandibularis: absent or rudimentary (0); present (1).

19. Cranium, fonticuli occipitales in adult birds: absent (0); present (1).

$20^{*}$. Fossa temporalis: short and, in caudal view, separated by wide space (0); deep, meeting or nearly meeting at level of the cerebellar prominence (1).

21. Pila otica with cluster of small pneumatic openings: no (0); yes (1).

22. Processus zygomaticus: present, variably developed (0); absent or vestigial (1). 
$23^{* *}$. Quadrate: processus oticus, capitulum, pneumatic foramen on caudal face: absent (0); present (1). P. mikkelseni was scored as (1) based on MGUH 29278. Livezey and Zusi [68] (character 554).

24t. Quadrate, processus oticus, two well-separated heads for articulation with os squamosum and os prooticum: absent (0); present (1). Pellornis mikkelseni was scored as (1) based on MGUH 29278.

25. Quadrate, condylus medialis, marked, rostrally projecting, concave articular surface: absent (0); present (1).

26t. Quadrate, condylus lateralis, large and with greatest extension in mediolateral direction; articular surface of mandible, "with single anteroposterior [ $\frac{1}{4}$ rostrocaudal $]$ ridge" and "lacking posteromedial $\left[\frac{1}{4}\right.$ caudomedial] and lateral walls": no (0); yes (1). P. mikkelseni was scored as (0) based on MGUH 29278. $27^{*}+$. Quadrate, processus orbitalis, narrowing sharply towards its rostral end, markedly thin, with pointed end: absent (0); present (1). P. mikkelseni was scored as (0) based on MGUH 29278.

28t. Mandible, long and strongly mediolaterally compressed processus retroarticularis: absent (0); present (1). P. mikkelseni was scored as (0) based on DK664.

29+. Mandible, processus medialis, long, narrow, and dorsally oriented: no (0); yes (1). P. mikkelseni was scored as (0) based on DK664.

$30^{*}$. Mandible, caudal end of with narrow, dorsally projecting hook-like projection: absent (0); present (1). P. mikkelseni was scored as (1) based on DK664.

31. Axis, corpus with pneumatic foramina on lateral sides: no (0); yes (1).

32. Axis, processus costales: present (0); absent (1).

33. Number of presacral vertebrae (all vertebrae cranial to synsacrum): $20-22$ (0); $18-19$ (1); 23 or more (2). This character was ordered.

34t. Several thoracic vertebrae fused to a notarium: no (0); yes (1). P. mikkelseni was scored as (0) based on MGUH 29278 and FUM 1681a.

35t. Thoracic vertebrae: at least part of series with subround, central articular surfaces (e.g., amphicoelous/opisthocoelous) that lack the dorsoventral compression and saddle-shaped articular surface seen in heterocoelous vertebrae (0); series completely heterocoelous (1). P. mikkelseni was scored as (1) based on FUM 1681a.

36. Caudalmost presacral vertebrae with deep lateral excavations: no (0); yes (1).

$37^{*}+$. Synsacrum, foramina intertransversaria: absent or few foramina present (0); well developed (1). P. mikkelseni was scored as (0) based on MGUH 29278 and FUM 1681a.

$38^{* *}+$. Preacetabular and acetabular synsacrum, ventral face, ventral sulcus of synsacrum: present (0); lost or barely discernable (1). P. mikkelseni was scored as (1) based on FUM 1681a. Musser and Cracraft [12] (character 282).

$39^{* *}+$. Ribs, proximo-ventral face, pneumatic foramen between tuberculum and capitulum: absent $(0)$; present (1). P. mikkelseni was scored as (0) based on FUM 1681a. Livezey [14] (character 129).

$40^{*}$. Furcula, processus acromialis long and slender: no (0); yes (1). P. mikkelseni was scored as (0) based on MGUH 29278.

$41^{* *}$. Scapula, tubercle on costal surface at cranial end: absent (0); present (1). This character is described as an apomorphy of Rallidae in Mayr [56], and noted to have a wider distribution by Ksepka [54]. Again, we consider this feature to be a synapomorphy of total group Ralloidea. P. mikkelseni was scored as (1) based on MGUH 29278.

$42^{* *}$. Scapula, large pneumatic foramen on medial surface: absent (0); present (1). Mayr [69] (character 1248).

43*. Coracoid, scapular facet: shallow (0), cuplike (1). P. mikkelseni was scored as (1) based on MGUH 29278.

44t. Coracoid, facies articularis clavicularis dorsoventrally wide and roofing the sulcus supracoracoideus, insertion of ligamentum acrocoracoprocoracoideum well developed and strongly ventromedially protruding: no (0); yes (1). P. mikkelseni was scored as (0) based on MGUH 29278. 
45*. Coracoid, processus procoracoideus extending as a sharp crest along midline of shaft (crista procoracoidei of Livezey [14]): absent (0); present (1). P. mikkelseni was scored as (1) based on MGUH 29278.

46. Coracoid, foramen nervi supracoracoidei: present (0); absent (1).

47. Coracoid, pneumatic foramen directly below facies articularis scapularis which does not penetrate shaft: absent (0); present (1). P. mikkelseni was scored as (0) based on MGUH 29278.

$48^{* *}$. Coracoid, shaft stout with midsection measuring more than $1 / 3$ width of extremitas sternalis: no (0); yes (1). Livezey [14] (character 12).

49. Coracoid, impressio musculi sternocoracoidei on dorsal surface of extremitas sternalis with pneumatic foramina: no (0); yes (1).

50*. Coracoid, dorsal view, extremitas sternalis forming three pointed projections: absent (0); present (1).

$51^{*}$. Sternum extremely elongate and very narrow: no (0); yes (1). We found this state to be indiscernible in P. mikkelseni due to diagenesis (emended from state 0 to state ?).

$52^{*}+$. Sternum, spina interna rostri: absent (0); present (1); present and fused to spina externa (2). P. mikkelseni was scored as (0) based on MGUH 29278.

53. Sternum, sulci coracoidei crossed: no (0); yes (1).

54. Sternum, well-developed, blade-like spina externa rostri: absent (0); present (1).

55. Sternum, number of processus costales: 3-4 (0); 5-6 (1); 7-8 (2). This character was ordered.

56. Sternum, facies visceralis with numerous pneumatic foramina along midline and lateral margins: no (0); yes (1).

$57^{* *}+$. Sternum, caudal margin, incisura and fenestra caudolateralis (if present), cranial extent: elongate, length of incisura and fenestra greater than $2 / 3$ craniocaudal length of corpus sterni, approaching terminis caudalis of processus costales sterni (0); intermediate-length of incisura and fenestra between $1 / 3$ and $2 / 3$ of craniocaudal length of corpus sterni (1); abbreviate-length of incisura and fenestra less than 1/3 craniocaudal length of corpus sterni (2). P. mikkelseni was scored as (3) based on MGUH 29278. Noncomparable where incisura (fenestra) and/or trabecula absent. Mayr [69] (character 1183).

$58^{* *}+$. Body of sternum, caudal margin, trabecula caudolateralis (if present): (sub)acuminate, variably oriented caudal terminal margin (0); cruciate, with terminal, transverse pila (1); rounded or (sub)rectangular, often obliquely aligned (2). P. mikkelseni was scored as (2) based on MGUH 29278. Noncomparable by absence of processus or incisura, fusion of the processus caudolateralis to the processus intermedius (i.e. Mergus serrator). Mayr [69] (character 1185).

59. Sternum, caudal margin: with four notches/fenestrae (0); with two notches/fenestrae (1) or without notches/fenestrae (2). Pellornis shows two deep incisurae on the left caudal margin of the sternum, and therefore this condition was coded as 0. P. mikkelseni was scored as (0) based on MGUH 29278.

$60^{*}$. Humerus, crista bicipitalis, aspect of the ventral border of the proximal end of humerus, caudal view: rounded or continuously curving (0), squared off (1). P. mikkelseni was scored as (0) based on MGUH 29278.

$61^{* *}+$. Humerus, long and narrow accessory scar for $\mathrm{m}$. supracoracoideus: absent (0); present (1). P. mikkelseni was scored as (0) based on MGUH 29278. This character is one of two created from the erroneous character 51 in the Bertelli et al. [35] dataset.

$62^{*}$. Humerus, foramina pneumatica at bottom of fossa pneumotricipitalis: absent (0), present (1).

$63^{*}$. Humerus, incisura capitis: not as follows (0), enclosed by distal projection of caput humeri (1), closed by transverse ridge (2).

$64^{*}$. Humerus, marked and well-developed fossa pneumotricipitalis dorsalis: no (0); yes (1). P. mikkelseni was scored as (0) based on MGUH 29278.

$65^{* *}+$. Humerus, tuberculum dorsale greatly elongated proximo-distally: no (0), yes, tuberculum dorsale at least 1.5 times as long as it is wide (1). P. mikkelseni was scored as (1) based on MGUH 29278. This character is the second of two created from the erroneous character 51 in the Bertelli et al. [35] dataset. 
$66^{* *}+$. Humerus, caudal surface of proximal shaft with centrally positioned, raised muscle attachment scar for m. latissimus dorsi, pars caudalis: absent (0); present (1). P. mikkelseni was scored as (0) based on MGUH 29278. Mayr [47] (character 20).

$67^{*}$. Humerus, proximal section of shaft with triangular cross section: no (0); yes (1). P. mikkelseni was scored as (1) based on MGUH 29278.

$68^{*}+$. Humerus, processus supracondylaris dorsalis greatly elongated proximo-distally: absent (0); present (1). P. mikkelseni was scored as (0) based on MGUH 29278.

69. Ulna, distinctly exceeding humerus in length: no (0), yes (1). P. mikkelseni was scored as (0) based on MGUH 29278.

70. Ulna, proximal end dorsoventrally compressed and cranioventrally inflected: yes (0), no (1).

71. Ulnare, tuberculum at area of insertion of ligamentum: no (0), yes (1).

$72^{* *}$. Carpometacarpus, marked ridge between processus pisiformis and trochlea carpalis: absent (0); present (1). Livezey [14] (character 242), Mayr [47] (character 24).

73t. Carpometacarpus, metacarpal III strongly bowed, delimiting a large spatium intermetacarpale: no (0), yes (1). P. mikkelseni was scored as (0) based on MGUH 29278.

$74^{* *}$. Alula, bearing small claw: absent (0); present (1). Livezey [14] (character 239).

75*. Maanual phalanx II-1: not perforated (0); perforated (1). P. mikkelseni was scored as (0) based on MGUH 29278.

76. Pelvis, number of vertebrae ankylosed in synsacrum: 11-12 (0); 13-14 (1); 15-16 (2); and 17-18 (3). This character was coded as ordered.

77t. Pelvis, cristae iliacae dorsales largely or completely fused dorsally with crista spinosa of synsacrum, thus forming a closed canalis iliosynsacralis: no (0); yes (1). P. mikkelseni was scored as (0) based on MGUH 29278.

78**. Pelvis, iliac blades and synsacrum: fused (0); unfused (1). Bertelli et al. [70] (character 178).

79. Pelvis, tuberculum preacetabulare: large (0); absent or vestigial (1). P. mikkelseni was scored as (0) based on MGUH 29278 and FUM 1681a.

$80^{* *}$. Pelvis, ala postacetabularis ilii, with laterally and directly downturned flange near midpoint: no (0); yes (1). Livezey [14] (character 286).

$81^{*}$. Pelvis, with deep incisura marginis caudalis in which the spinae dorsolateralis ilii reach almost as far caudally as the processus terminalis ischii: absent (0); present (1).

$82^{* *}$. Pelvis, ischium, processus terminalis ischii, straight, thin, elongate and caudally tapered to a subrectangular terminus: no, processes truncate or essentially absent (0); yes (1); no, processes elongate but not as described (2). Noncomparable for Paleognathae.

83+. Pelvis, deeply excavated recessus caudalis fossae: absent (0); present (1). P. mikkelseni was scored as (1) based on FUM 1681a.

84t. Femur, crista trochanteris markedly projected cranially: no (0); yes (1). P. mikkelseni was scored as (1) based on FUM 1681a.

85t. Femur, pneumatic foramen on cranio-lateral side of proximal end: absent (0); present (1). P. mikkelseni was scored as (0) based on FUM 1681a.

86t. Tibiotarsus, prominent tubercle latero-distal to pons supratendineus (or corresponding area in taxa without supratendinal bridge): absent (0); present (1). P. mikkelseni was scored as (0) based on DK664. See Mayr and Clarke [44], Figure 9g.

87. Tibiotarsus, distal rim of condylus medialis distinctly notched: no (0); yes (1).

$88^{* *}+$. Tarsometatarsus, arcus extensorius (ossified retinaculum extensorium tarsometatarsi): absent (0); present (1). Mayr [69] (character 35). P. mikkelseni was scored as (1) based on DK664.

89t. Tarsometatarsus, hypotarsus with well-developed cristae/sulci: no (0), yes (1). P. mikkelseni was scored as (1) based on DK664.

$90^{* *}+$. Tarsometatarsus, crista medialis hypotarsi: absent (0); reduced to proximodistally short lamella (1); strongly developed (2). Mayr [47] (character 31). P. mikkelseni was scored as (2) based on DK664. 
91t. Tarsometatarsus, hypotarsus, tendon of musculus flexor digitorum longus enclosed in bony canal: no (0); yes (1). P. mikkelseni was scored as (1) based on DK664.

92. Tarsometatarsus, trochlea metatarsi II plantarly deflected and distal end reaching much less far distally than distal end of trochlea metatarsi IV: yes (0), no (1).

93t. Tarsometatarsus, hypotarsus, furrow/canal for tendon of musculus flexor perforatus digiti II marked and laterally bordered by a proximodistally long and plantarly protruding crista lateralis: absent (0); present (1). P. mikkelseni was scored as (1) based on DK664.

94. Tarsometatarsus, fourth and third phalanx of fourth toe, relative length: fourth phalange longer (0); both phalanges of equal length (1); fourth phalange shorter (2). This character was ordered.

$95^{*}$. Three anterior toes notably elongated: absent (0); present (1).

96. Hallux: not as follows (0); greatly reduced (proximal phalanx very short, measuring less than half of the length of the proximal phalanx of third toe) or completely absent (1).

$97^{* *}$. Hallux, bowed: no (0); yes (1).

98. Musculus caudofemoralis, pars caudalis: present (0); absent or poorly developed (1).

99*. Intratendinous ossification in hindlimbs: absent (0); present (1). P. mikkelseni was scored as (1) based on MGUH 29278.

100. Upper beak, lamellae for filter feeding: absent (0); vestigial (1); well developed (2). This character was ordered.

101. Wing: diastataxic (0); eutaxic (1).

102. Enzyme malate dehydrogenase with unusually slow motility ( $55 \%$ as fast as that of galliform birds): no (0); yes (1).

\section{References}

1. Ericson, P.G.P.; Anderson, C.L.; Britton, T.; Elzanowski, A.; Johansson, U.S.; Källersjö, M.; Ohlson, J.I.; Parsons, T.J.; Zuccon, D.; Mayr, G. Diversification of Neoaves: Integration of molecular sequence data and fossils. Biol. Lett. 2006, 2, 543-547. [CrossRef] [PubMed]

2. Jarvis, E.D.; Mirarab, S.; Aberer, A.J.; Li, B.; Houde, P.; Li, C.; Ho, S.Y.; Faircloth, B.C.; Nabholz, B.; Howard, J.T.; et al. Whole-genome analyses resolve early branches in the tree of life of modern birds. Science 2014, 346, 1320-1331. [CrossRef] [PubMed]

3. Prum, R.O.; Berv, J.S.; Dornburg, A.; Field, D.J.; Townsend, J.P.; Lemmon, E.M.; Lemmon, A.R. A comprehensive phylogeny of birds (Aves) using targeted next-generation DNA sequencing. Nature 2015, 526, 569-573. [CrossRef] [PubMed]

4. Ksepka, D.; Phillips, M.J. Avian diversification patterns across the K-Pg boundary: Influence of calibrations, datasets, and model misspecification. Ann. Mo. Bot. Gard. 2015, 100, 300-328. [CrossRef]

5. Claramunt, S.; Cracraft, J.L. A new time tree reveals Earth history's imprint on the evolution of modern birds. Sci. Adv. 2015, 1, e1501005. [CrossRef] [PubMed]

6. Berv, J.S.; Field, D.F. Genomic Signature of an Avian Lilliput Effect across the K-Pg Extinction. Syst. Biol. 2018, 67, 1-13. [CrossRef] [PubMed]

7. Field, D.J.; Berv, J.S.; Hsiang, A.Y.; Lanfear, R.; Landis, M.J.; Dornburg, A. Timing the extant avian radiation: The rise of modern birds, and the importance of modeling molecular rate variation. PeerJ Prepr. $2019,7$. [CrossRef]

8. Ericson, P.G.P. Evolution of terrestrial birds in three continents: Biogeography and parallel radiations. J. Biogeogr. 2012, 39, 813-824. [CrossRef]

9. Mayr, G. Avian higher level biogeography: Southern Hemispheric origins or Southern Hemispheric relicts? J. Biogeogr. 2017, 44, 950-962. [CrossRef]

10. Cracraft, J.; Claramunt, S. Conceptual and analytical worldviews shape differences about global avian biogeography. J. Biogeogr. 2017, 44, 950-962. [CrossRef]

11. Field, D.J.; Hsiang, A.Y. A North American stem turaco, and the complex biogeographic history of modern birds. BMC Evolut. Biol. 2018, 18, 102. [CrossRef] [PubMed] 
12. Musser, G.M.; Cracraft, J. A new morphological dataset reveals a novel relationship for the adzebills of New Zealand (Aptornis) and provides a foundation for total evidence neoavian phylogenetics. Am. Mus. Novit. 2019, 3927, 1-70. [CrossRef]

13. Houde, P.; Cooper, A.; Leslie, E.; Shand, A.E.; Montano, G.A. Phylogeny and evolution of $12 S$ rDNA in gruiformes (Aves). In Avian Molecular Evolution and Systematics; Mindell, D.P., Ed.; Academic Press: San Diego, CA, USA, 1997; pp. 117-154.

14. Livezey, B.C. A phylogenetic analysis of the Gruiformes (Aves) based on morphological characters, with an emphasis on the rails (Rallidae). Philos. Trans. R. Soc. Lond. B 1998, 353, 2077-2151. [CrossRef]

15. Fain, M.G.; Krajewski, C.; Houde, P. Phylogeny of "core Gruiformes" (Aves: Grues) and resolution of the Limpkin-Sungrebe problem. Mol. Phylogenet. Evolut. 2007, 43, 515-529. [CrossRef] [PubMed]

16. García, R.J.C.; Gibb, G.C.; Trewick, S.A. Eocene Diversificaiton of Crown Group Rails (Aves: Gruiformes: Rallidae). PLoS ONE 2014, 9. [CrossRef] [PubMed]

17. García, R.J.C.; Gibb, G.C.; Trewick, S.A. Deep global evolutionary radiation in birds: Diversification and trait evolution in the cosmopolitan bird family Rallidae. Mol. Phylogenet. Evolut. 2014, 81, 96-108. [CrossRef]

18. Boast, A.P.; Chapman, B.; Herrera, M.B.; Worthy, T.H.; Scofield, R.P.; Tennyson, A.J.D.; Houde, P.; Bunce, M.; Cooper, A.; Mitchell, K.J. Mitochondrial genomes from New Zealand's extinct Adzebills (Aves: Aptornithidae: Aptornis) support a sister-taxon relationship with the Afro-Madagascan Sarothruridae. Diversity 2019, 11, 24. [CrossRef]

19. Mayr, G. Paleogene Fossil Birds; Springer: Berlin/Heidelberg, Germany, 2009.

20. Mayr, G. Avian Evolution: The Fossil Record of Birds and Its Paleobiological Significance; John Wiley and Sons Ltd.: West Sussex, UK, 2017.

21. Mayr, G.; Smith, T. New Paleocene bird fossils from the North Sea Basin in Belgium and France. Geol. Belg. 2019, 22, 35-46. [CrossRef]

22. Olson, S.L. A Synopsis of the Fossil Rallidae Rails of the World: A Monograph of the Family Rallidae; Codine: Boston, MA, USA, 1977.

23. Cracraft, J. Systematics and evolution of the Gruiformes (class Aves): 3. Phylogeny of the suborder Grues. Bull. Am. Mus. Nat. Hist. 1973, 151, 1.

24. Hesse, A. A new species of Messelornis (Aves: Gruiformes: Messelornithidae) from the Middle Eocene Green River Formation. In Contributions in Science: Papers in Avian Paleontotogy Honoring Pierce Brodkorb; Campbell, K.E., Ed.; Los Angeles County Museum of Natural History: Los Angeles, CA, USA, 1992; Number 330; pp. 171-178.

25. Hesse, A. Die Messelornithidae-eine neue Familie der Kranichartigen (Aves: Gruiformes: Rhynocheti) aus dem Tertiär Europas und Nordamerikas. J. Ornithol. 1988, 129, 83-95. [CrossRef]

26. Mayr, G. The early Eocene birds of the Messel fossil site: A 48 million-year-old bird community adds a temporal perspective to the evolution of tropical avifaunas. Biol. Rev. 2017, 92, 1174-1188. [CrossRef] [PubMed]

27. Grande, L. The Lost World of Fossil Lake: Snapshots from Deep Time; The University of Chicago Press: Chicago, IL, USA, 2013.

28. Weidig, I. New birds from the Lower Eocene Green River Formation, North America. In Proceedings of the VII International Meeting of the Society of Avian Paleontology and Evolution, Sydney, Australia, 18-23 August 2008 ; Boles, W.E., Worthy, T.H., Eds.; Records of the Australian Museum, Australian Museum: Sydney, Australia, 2010; pp. 29-44.

29. Mourer-Chauviré, C. The Messelornithidae (Aves: Gruiformes) from the Paleogene of France. Cour. Forsch. Senckenberg 1995, 181, 95-105.

30. Hesse, A. Die Beschreibung der Messelornithidae (Aves: Gruiformes: Rhynocheti) aus dem Alttertiär Europas und Nordamerikas. Cour. Forsch. Senckenberg 1990, 128, 1-176.

31. Peters, D.S. Zoogeographical relationships of the Eocene avifauna from Messel (Germany). In Proceedings of the Acta XX Congressus Internationalis Ornithologici, Christchurch, New Zealand, 2-9 December 1990; Bell, B.D., Cossee, R.O., Flux, J.E.C., Heather, B.D., Hitchmough, R.A., Robertson, C.J.R., Williams, M.J., Eds.; New Zealand Ornithological Congress Trust Board: Christchurch, New Zealand, 1991; pp. 572-577.

32. Feduccia, A. The Origin and Evolution of Birds; Yale University Press: New Haven, CA, USA, 1996.

33. Cracraft, J. Avian evolution, Gondwana biogeography and the Cretaceous-Tertiary mass extinction event. Proc. R. Soc. Lond. B 2001, 268, 459-469. [CrossRef] [PubMed] 
34. Mayr, G. Phylogenetic relationships of the early Tertiary Messel rails (Aves, Messelornithidae). Senckenbergiana Lethaea 2004, 84, 317-322. [CrossRef]

35. Bertelli, S.; Chiappe, L.M.; Mayr, G. A new Messel rail from the early Eocene fur Formation of Denmark (Aves, Messelornithidae). J. Syst. Paleontol. 2011, 9, 551-562. [CrossRef]

36. Wang, M.; Mayr, G.; Zhang, J.; Zhou, Z. Two new skeletons of the enigmatic, rail-like avian taxon Songzia Hou, 1990 (Songziidae) from the early Eocene of China. Alcheringa Aust. J. Paleontol. 2012, 36, 487-499. [CrossRef]

37. Hou, L.H. An Eocene bird from Songzi, Hubei province. Vertebr. Palasiat. 1990, 28, 34-42.

38. Mayr, G.; Hervet, S.; Buffetaut, E. On the diverse and widely ignored Paleocene avifauna of Menat (Puy-de-Dôme, France): New taxonomic records and unusual soft tissue preservation. Geol. Mag. 2019, 156, 572-584. [CrossRef]

39. Hoch, E. Notes on palaeornithology and on a New Bird from the Early Tertiary North Sea Region. Geological Society of Denmark, Online Series, 1. 1997. Available online: http://www.2dgf.dk/online/bird.htm (accessed on 15 September 2017).

40. Kristoffersen, A.V. The Avian Diversity in the Latest Paleocene-Earliest Eocene Fur Formation, Denmark. Unpublished. Ph.D. Thesis, Geological Institute, University of Copenhagen, København, Denmark, 2002.

41. Chambers, L.M.; Pringle, M.; Fitton, G.; Larsen, L.M.; Pedersen, A.K.; Parrish, R. Recalibration of the Palaeocene-Eocene boundary (P-E) using high precision $\mathrm{U}-\mathrm{Pb}$ and $\mathrm{Ar}-\mathrm{Ar}$ isotopic dating: Abstracts. In Proceedings of the EGS-AGU-EUG Joint Assembly, Nice, France, 6-11 April 2003; pp. 9681-9682.

42. Schultz, B.P.; Muserum, Division of Natural History, Havnevej, Skive, Denmark. Personal communication, 2019.

43. Baumel, J.J.; Witmer, L.M. Osteologia. In Handbook of Avian Anatomy: Nomina Anatomica Avium; Baumel, J.J., King, A.S., Breazile, J.E., Evans, H.E., Vanden Berge, J.C., Eds.; Publications of the Nuttall Ornithological Club: Cambridge, MA, USA, 1993; pp. 45-132.

44. Mayr, G.; Clarke, J.A. The deep divergences of neornithine birds: A phylogenetic analysis of morphological characters. Cladistics 2003, 19, 527-553. [CrossRef]

45. Worthy, T.H.; Boles, W.E. Australlus, a New Genus for Gallinula disneyi (Aves: Rallidae) and a Description of a New Species from Oligo-Miocene Deposits at Riversleigh, Northwestern Queensland, Australia. Rec. Aust. Mus. 2011, 63, 61-77. [CrossRef]

46. Mayr, G. A chicken-sized crane precursor from the early Oligocene of France. Naturwissenschaften 2005, 92, 389-393. [CrossRef] [PubMed]

47. Mayr, G. Parvigruidae (Aves, core Gruiformes) from the early Oligocene of Belgium. Paleodivers. Paleoenviron. 2013, 93, 77-89. [CrossRef]

48. Olson, S. A classification of the Rallidae. Wilson Bull. 1973, 65, 381-416.

49. Hackett, S.J.; Kimball, R.T.; Reddy, S.; Bowie, R.C.; Braun, E.L.; Braun, M.J.; Chojnowski, J.L.; Cox, W.A.; Han, K.L.; Harshman, J.; et al. A phylogenomic study of birds reveals their evolutionary history. Science 2008, 320, 1763-1768. [CrossRef] [PubMed]

50. O'Leary, M.A.; Kaufman, S.G. MorphoBank 3.0: Web Application for Morphological Phylogenetics and Taxonomy. 2012. Available online: https://morphobank.org/index.php/FAQ/Index (accessed on 15 September 2017).

51. Field, D.J.; Lynner, C.; Brown, C.; Darroch, S.A.F. Skeletal Correlates for Body Mass Estimation in Modern and Fossil Flying Birds. PLoS ONE 2013, 8, e82000. [CrossRef] [PubMed]

52. Swofford, D.L. PAUP* Phylogenetic Analysis Using Parsimony ( ${ }^{*}$ and Other Methods); Version $4.0 a 164$ (X86); Sinauer Associates: Sunderland, MA, USA, 2002.

53. Linnaeus, C. Systema Naturae per Regna Tria Naturae, Secundum Classes, Ordines, Genera, Species, Cum Characteribus, Differentiis, Synonymis, Locis; Photographic Facsimile; British Museum of Natural History: London, UK, 1758.

54. Pycraft, W.P. On the morphology and phylogeny of the Palaeognathae (Ratitae and Crypturi) and Neognathae (Carinatae). Trans. Zool. Soc. Lond. 1900, 15, 149-290. [CrossRef]

55. Vinther, J.; Briggs, D.E.G.; Prum, R.O.; Saranathan, V. The colour of fossil feathers. Biol. Lett. 2008, 4. [CrossRef]

56. Mayr, G. A rail (Aves, Rallidae) from the early Oligocene of Germany. ARDEA 2006, 94, $23-31$.

57. Ksepka, D.T. Broken gears in the avian molecular clock: New phylogenetic analyses support stem galliform status for Gallinuloides wyomingensis and rallid affinities for Amitabha urbsinterdictensis. Cladistics 2009, 25, 173-197. [CrossRef] 
58. Colleary, C.; Dolocan, A.; Gardner, J.; Singh, S.; Wuttke, M.; Rabenstein, R.; Habersetzer, J.; Schaal, S.; Feseha, M.; Clemens, M.; et al. Chemical, experimental, and morphological evidence for diagenetically altered melanin in exceptionally preserved fossils. Proc. Natl. Acad. Sci. USA 2015, 112, 12592-12597. [CrossRef] [PubMed]

59. Zusi, R.L. A functional and evolutionary analysis of rhynchokinesis in birds. Smithson. Contrib. Zool. 1984, 395, 1-40. [CrossRef]

60. Dunning, J.B. Handbook of Avian Body Masses, 2nd ed.; CRC Press: Boca Raton, FL, USA, 2007.

61. Feduccia, A. Avian extinction at the end of the Cretaceous: Assessing the magnitude and subsequent explosive radiation. Cretac. Res. 2014, 50,1-15. [CrossRef]

62. Suh, A. The phylogenomic forest of bird trees contains a hard polytomy at the root of Neoaves. Zool. Scr. 2016, 45, 50-62. [CrossRef]

63. Fain, M.G.; Houde, P. Parallel radiations in the primary clades of birds. Evolution 2004, 58, $2558-2573$. [CrossRef] [PubMed]

64. Reddy, S.; Kimball, R.T.; Pandey, A.; Hosner, P.A.; Braun, M.J.; Hackett, S.J.; Han, K.L.; Harshman, J.; Huddleston, C.J.; Kingston, S.; et al. Why do phylogenomic data sets yield conflicting trees? Data type influences the avian tree of life more than taxon sampling. Syst. Biol. 2017, 66, 857-879. [CrossRef] [PubMed]

65. Field, D.J.; Bercovici, A.; Berv, J.S.; Regan, D.; Fastovsky, D.E.; Lyson, T.R.; Vajda, V.; Gauthier, J.A. Early evolution of modern birds structured by global forest collapse at the end-Cretaceous mass extinction. Curr. Biol. 2018, 28, 1825-1831. [CrossRef] [PubMed]

66. Mayr, G.; Smith, R. Ducks, rails and limicoline waders (Aves: Ansriformes, Gruiformes, Charadriiformes) form the lowermost Oligocene of Belgium. Geobios 2001, 334, 547-561. [CrossRef]

67. De Pietri, V.L.; Mayr, G. Reappraisal of early Miocene rails (Aves, Rallidae) from central France: Diversity and character evolution. J. Zool. Syst. Evolut. Res. 2014, 52, 312-322. [CrossRef]

68. Livezey, B.C.; Zusi, R.L. Higher-order phylogeny of modern birds (Theropoda, Aves: Neornithes) based on comparative anatomy: I. methods and characters. Bull. Carnegie Mus. Nat. Hist. 2006, 37, 1-95. [CrossRef]

69. Mayr, G. The phylogenetic relationships of the early Tertiary Primoscenidae and Sylphornithidae and the sister taxon of crown group piciform birds. J. Ornithol. 2004, 145, 188-198. [CrossRef]

70. Bertelli, S.; Lindowm, B.E.K.; Dyke, G.J.; Mayr, G. Another charadriiform-like bird from the Lower Eocene of Denmark. Paleontol. J. 2013, 11, 1282-1301. [CrossRef] 